\title{
Corporate Investment: Does Market Valuation Matter in the Aggregate?
}

DOES CHARTING the course of $q$-the ratio of the market value of firms to the replacement cost of their assets-help in predicting investment by nonfinancial corporations? This study seeks to answer this question. In the process, it also analyzes the behavior of the after-tax rate of return on capital and the lag from new orders for capital goods to shipments to obtain consistent specifications and to check on the compatibility of results. Special attention is paid to the construction and interpretation of $q$ and how it functions in concert with nonfinancial variables in the orders and investment equations.

Balance-sheet variables and stock-market appraisals obviously affect the cost of capital of individual firms as well as their willingness and ability to invest. But their influence on aggregate investment behavior is less clear. In fact, studies conducted up to the mid-sixties generally found that debt-equity ratios or debt-capacity problems had little discernible effect

Note: I am indebted to Burton G. Malkiel, Charles A. Waite, John C. Musgrave, Gerald Silverstein, Robert W. Kilpatrick, Cynthia F. Wallace, Helen S. Tice, Murray F. Foss, Moody's Investors Service, Inc., and Wharton Econometric Forecasting Associates, Inc., for supplying data and advice. Special thanks are owed to my research assistant, Harry S. Watson, for performing far more than routine analytical tasks, and to my colleague, R. Jeffery Green, for advice. Expert and selfless advance comments by the discussants, and other Brookings Panel members, saved me from several major errors. 
on the investment response of corporations to profits and sales. ${ }^{1}$ General developments in the stock market were seen as reflecting profit and sales expectations and credit conditions without much independent explanatory power. ${ }^{2}$

Since that time, however, significant drifts in financial variables have occurred, with debt-equity ratios generally rising and the market valuation of firms relentlessly falling relative to the replacement cost of their assets. Furthermore, James Tobin and William C. Brainard have recently emphasized that aggregate market valuations matter because "investment is stimulated when capital is valued more highly in the market than it costs to produce it, and discouraged when its valuation is less than its replacement cost." 3 They maintain that $q$ contains important information about investment incentives that cannot be conveyed adequately by traditional variables such as interest rates. ${ }^{4}$ Rather, investment incentives vary with the difference between the marginal efficiency of investment and the cost rate of capital, and changes in interest rates are only one of several factors that may alter this difference. Since these suspicions about the role of interest rates may be especially relevant in the inflationary and risk-laden environment of the seventies, it is time for another look.

1. About a decade after the publication of Franco Modigliani and Merton $\mathrm{H}$. Miller, "The Cost of Capital, Corporation Finance and the Theory of Investment," American Economic Review, vol. 48 (June 1958), pp. 261-97, which gave a theoretical justification for the use of balance-sheet and market-value data, they became more common in aggregate investment equations and in estimating appreciation rates in expressions for the nominal cost of capital and for the unit rental of capital. The first empirical use of $q$-type variables appears to have been made by Yehuda Grunfeld, "The Determinants of Corporate Investment," in Arnold C. Harberger, ed., The Demand for Durable Goods (University of Chicago Press, 1960), pp. 21166, and Alan Greenspan, "Stock Prices and Capital Evaluation," in American Statistical Association, Proceedings of the Business and Economic Statistics Section (1959), pp. 14-26.

2. For instance, Robert W. Resek used stock-market indexes simply as a leading indicator of expected output. See his "Investment by Manufacturing Firms: A Quarterly Time Series Analysis of Industry Data," Review of Economics and Statistics, vol. 48 (August 1966), pp. 322-33.

3. William C. Brainard and James Tobin, "Pitfalls in Financial Model Building," American Economic Review, vol. 58 (May 1968), p. 104.

4. See James Tobin and William C. Brainard, "Asset Markets and the Cost of Capital," in Bela Belassa and Richard Nelson, eds., Economic Progress, Private Values, and Public Policy, Essays in Honor of William Fellner (Amsterdam: NorthHolland, 1977), pp. 235-62, especially p. 236. See also John H. Ciccolo, Jr., "A Linkage Between Product and Financial Markets-Investment and ' $q$ '," in "Four Essays on Monetary Policy” (Ph.D. dissertation, Yale University, 1975), pp. 39-45. 
Interest in the securities-valuation issue does not spring solely from scholarly preoccupations with the proper integration of financial and "real" variables in macroeconomic models. ${ }^{5}$ Rather, if $q$ is a powerful and leading determinant of investment by nonfinancial corporations, the behavior of that variable and of the stock market to date leaves little hope that the long-awaited investment boom will materialize in 1978. On the other hand, if the significance of $q$ is primarily microeconomic, with changing $q$ differentials guiding the allocation of investment within and among firms and industries just as changes in relative prices do, then the absolute level of aggregate $q$ would have little bearing on the outlook for investment in the short run. In that case, the difference between the marginal and average $q$, rather than the difference between the actual level of $q$ and unity, may determine investment incentives in the aggregate. If corporations can expect to raise $q$ so as to benefit existing shareholders, they may be inclined to use retained earnings for new investments in their business regardless of the present level of $q$, as long as their $q$ is no lower than that of other corporations. Furthermore, even if $q$ is far below unity, corporate managers may not reduce retained earnings through increased dividend payout if they believe doing so would preclude a rise in $q$.

By way of background, the first two sections of this paper show the derivation of $q$, of certain tax-change variables, and of several other variables with which $q$ may interact. The behavior of the after-tax rate of return on capital will be used as a guide to constructing the appropriate phaseout pattern applied to permanent tax changes. This analysis also complements the work of Martin Feldstein and Lawrence Summers on before-tax rates. ${ }^{6}$

Specification issues are examined in the third section. To assure that the lags selected in the orders equations are consistent with the lags in the investment equations, the lags from capital-goods orders to shipments are analyzed. The resulting estimates may also be of considerable interest by themselves, since orders for capital goods (equipment) are an important indicator of the investment outlook entering into the leading indi-

5. See James Tobin, "A General Equilibrium Approach to Monetary Theory," Journal of Money, Credit and Banking, vol. 1 (February 1969), pp. 15-29; Duncan K. Foley and Miguel Sidrauski, Monetary and Fiscal Policy in a Growing Economy (Macmillan, 1971); and Karl Brunner and Allan H. Meltzer, "Money, Debt, and Economic Activity," Journal of Political Economy, vol. 80 (September/October 1972), pp. 951-77.

6. "Is the Rate of Profit Falling?" BPEA, 1:1977, pp. 211-27. 
cators of the National Bureau of Economic Research. Such orders must be affected before investment can respond, and variables purporting to explain investment must be viewed with suspicion if they or their lag specifications do not function in a way that is corroborated by orders. With this link clarified, $q$ can be tested on its own and in conjunction with other variables in both the preliminary orders and investment equations reported in the fourth section.

If $q$ is influenced by some of the nonfinancial variables included in these equations, uninformative estimates may result from the use of unadjusted values of $q$. The fourth section thus examines the information content of $q$. With $q$ free from the influence of nonfinancial variables, the fifth section focuses on the role of the residual, presumably financial, determinants of $q$ in capital-goods orders and investment. A final section offers a guarded conclusion about the usefulness of $q$ in aggregate investment equations.

\section{Quarterly Estimates of $q$ for Nonfinancial Corporations}

The measurement of $q$ is far from clear-cut because the literature has used diverse means to approximate both the market value of firms and the replacement cost of incomplete sets of assets. Furthermore, some degree of arbitrariness is inevitably involved when net interest paid by nonfinancial corporations is capitalized to infer the market value of the net interest-bearing liabilities outstanding or when noninterest-bearing financial assets are netted against the book value of the corresponding liabilities to obtain an appropriate addition to the replacement cost of fixed assets, inventories, and land. For this reason the derivation of $q$ must be explained in some detail.

Since $q$ is defined as the ratio of the market value of the liabilities of nonfinancial corporations to the replacement cost of their assets, the denominator of $q$ is obtainable by adding the net noninterest-bearing financial assets to the replacement cost of net fixed capital, inventories, and land, which are identified as "other assets" in table $1 .{ }^{7}$ While quar-

7. Net noninterest-bearing financial assets are calculated from unpublished flowof-funds statistics from the Board of Governors of the Federal Reserve System, dated March 19, 1977, as the sum of demand deposits and currency, miscellaneous assets, and net trade credit minus the sum of profit taxes payable and miscellaneous liabilities outstanding. 


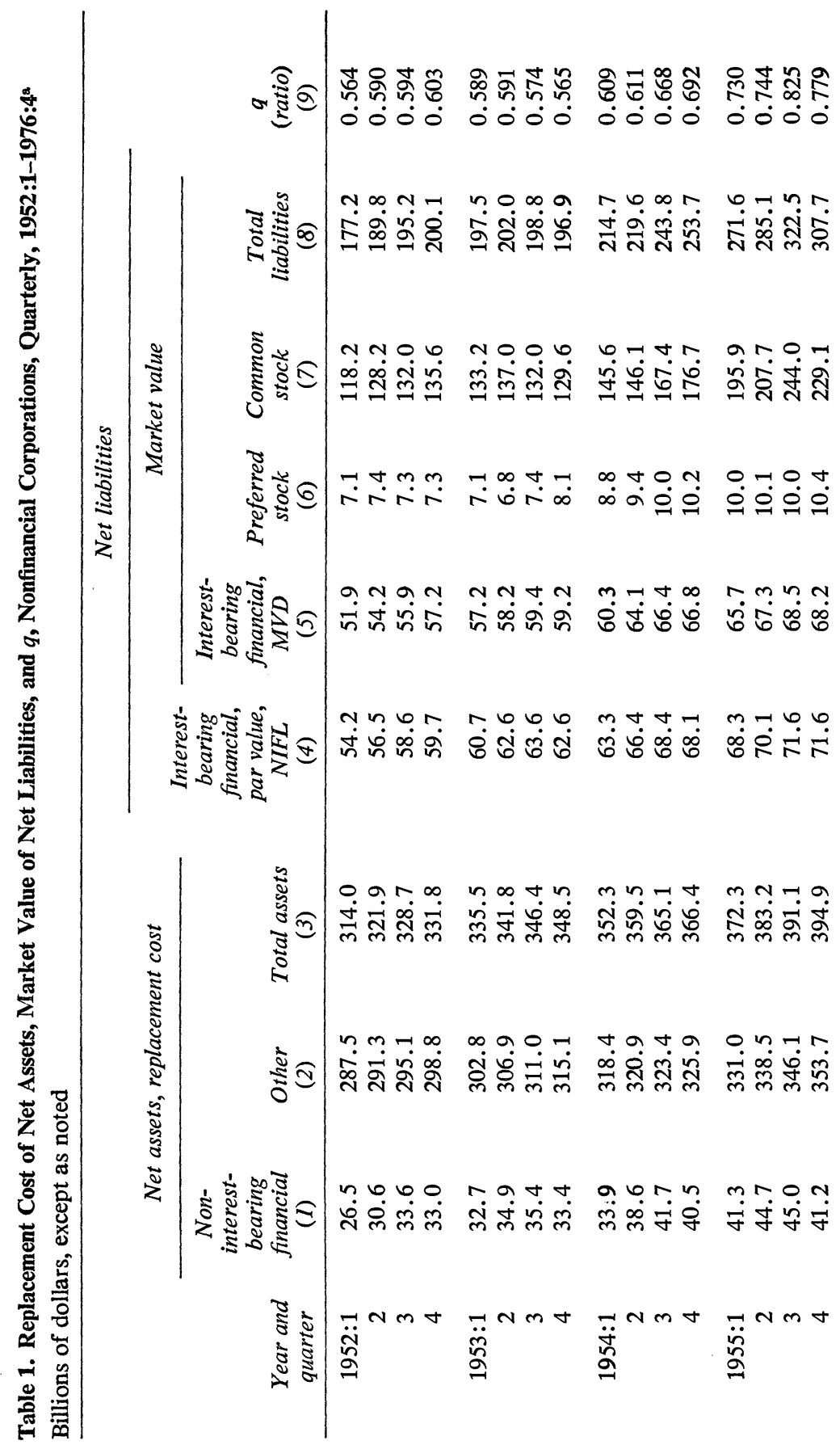




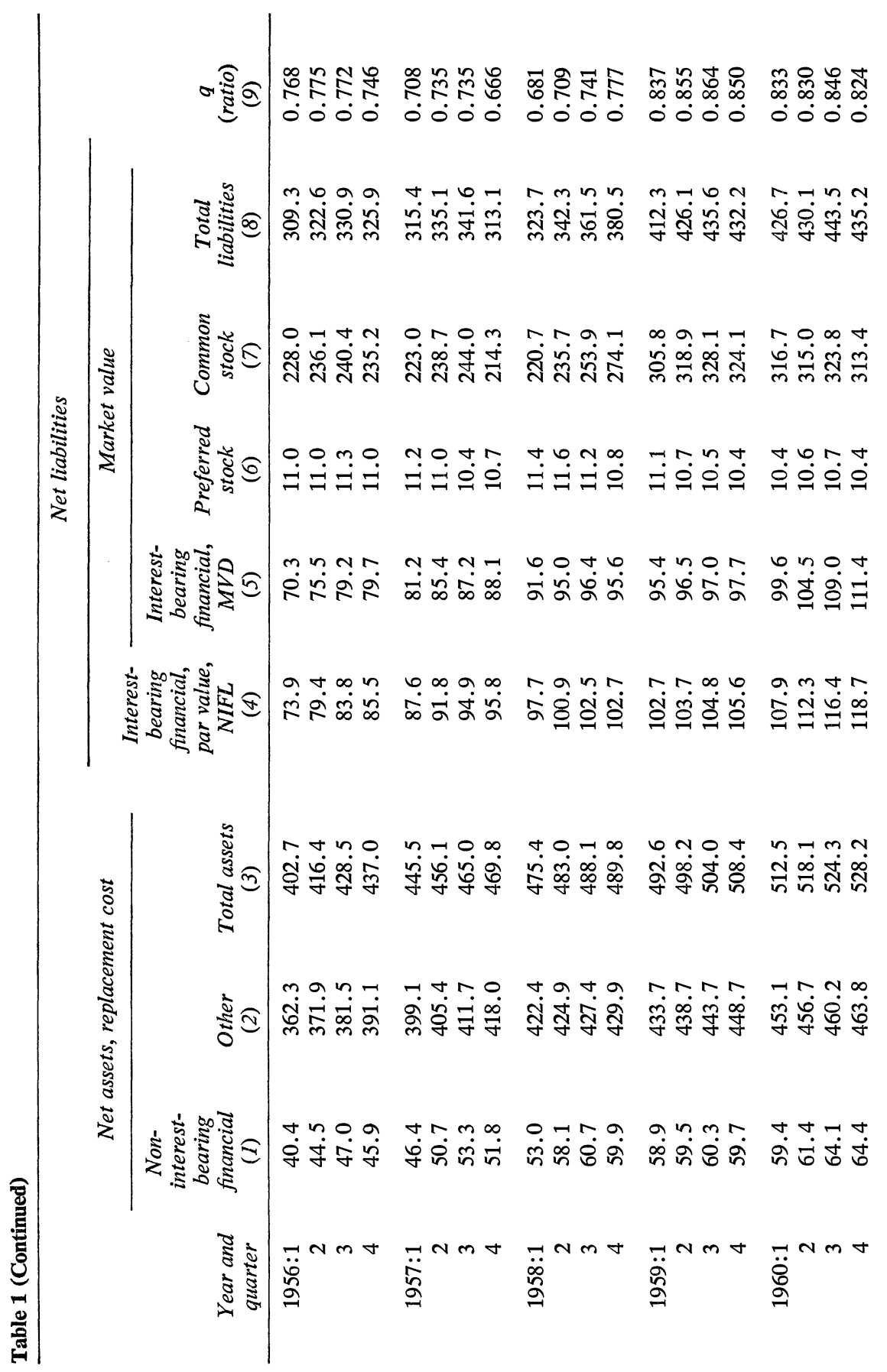




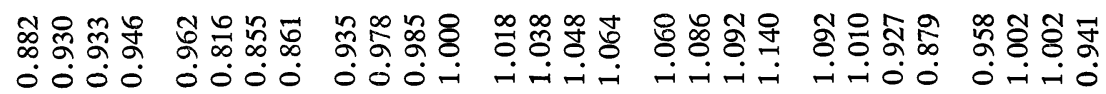

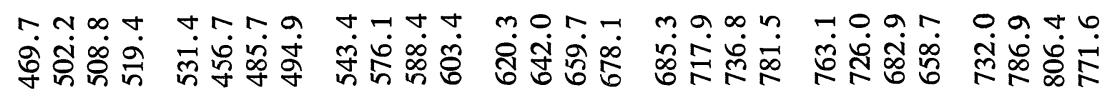

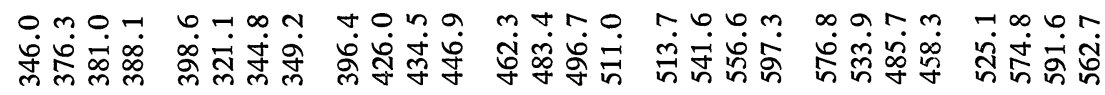

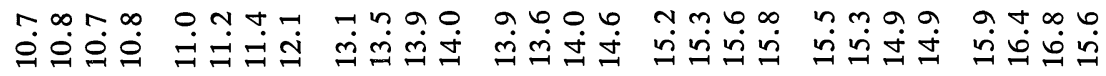

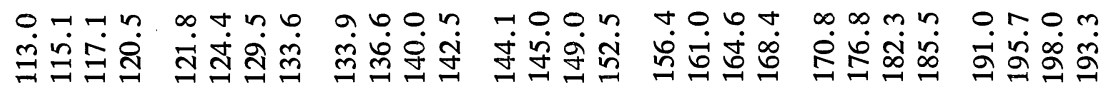

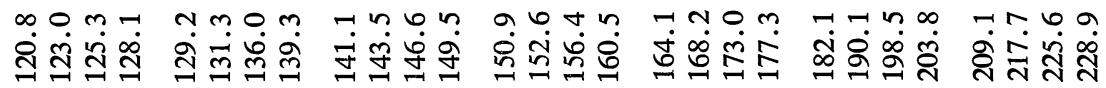

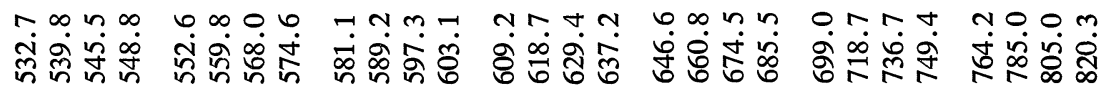
do

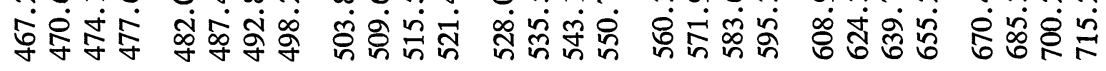

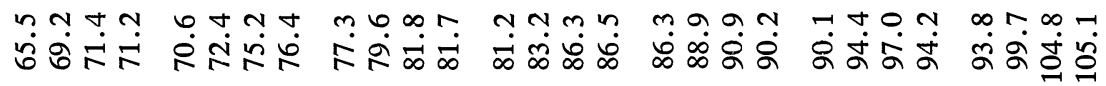

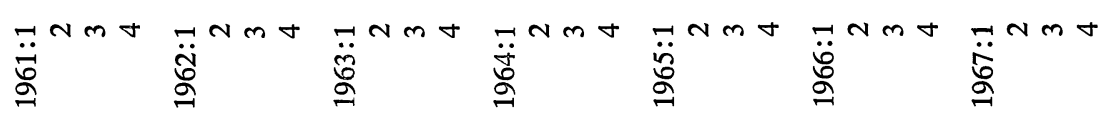




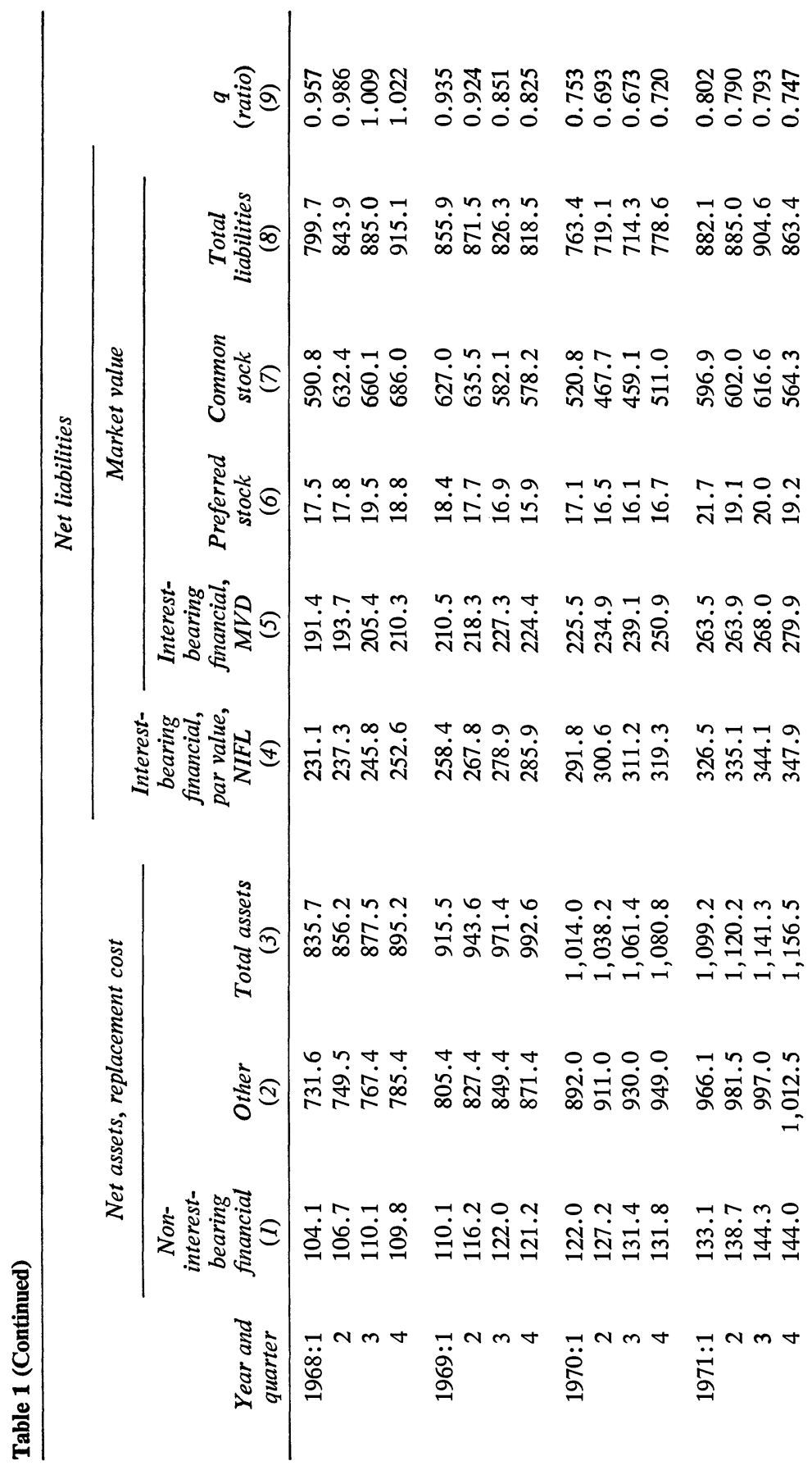




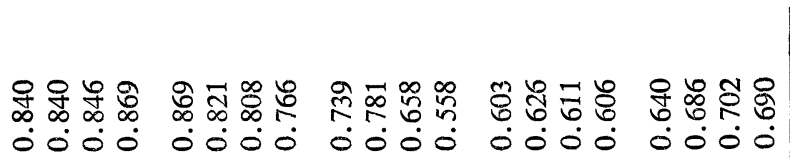

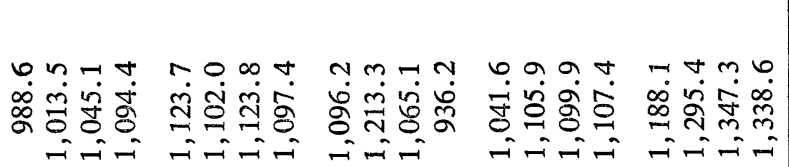

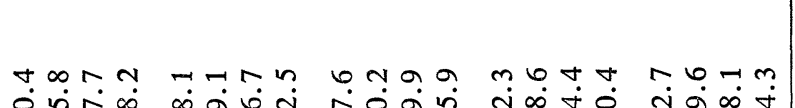

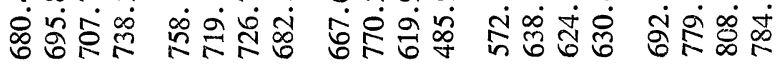

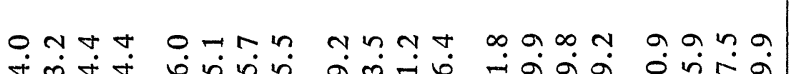

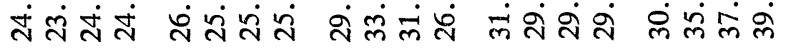

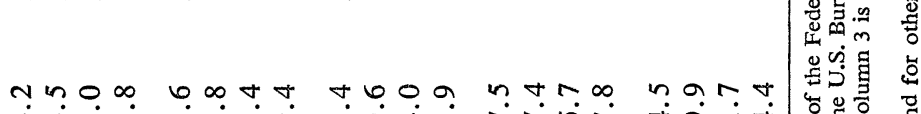

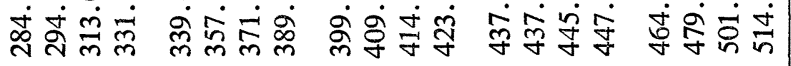

$-0000-\pi m-\sigma a \infty$ thm-

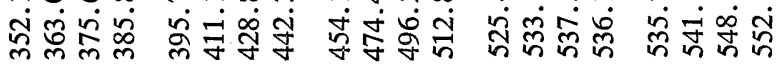

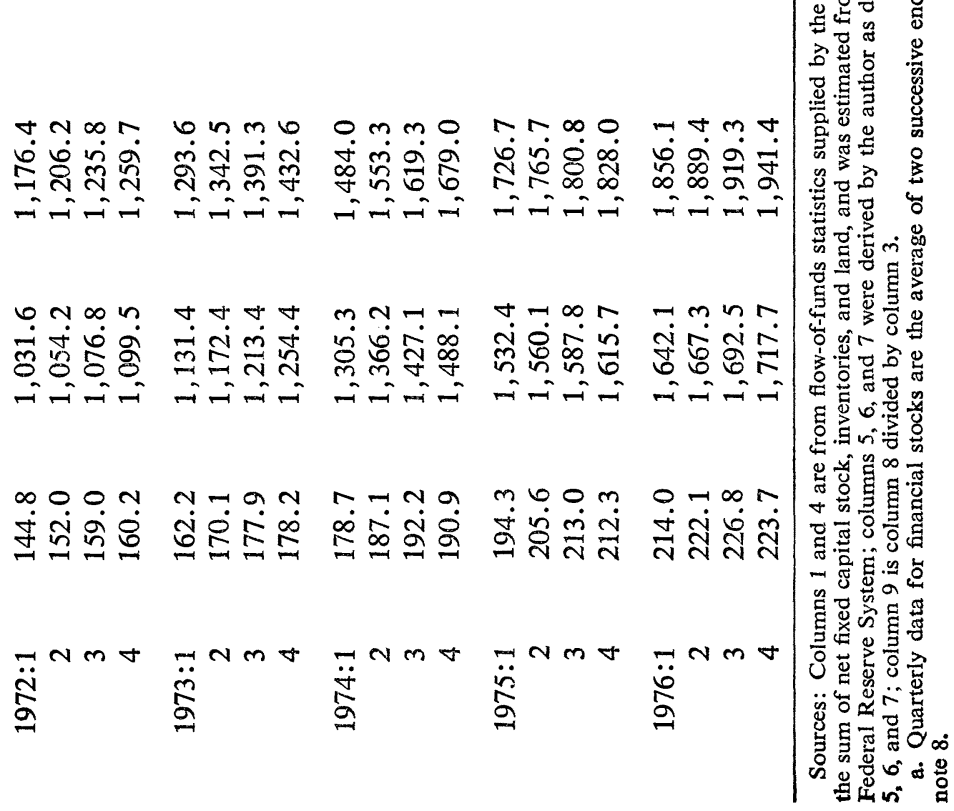


terly data on financial assets are available from the flow-of-funds accounts, quarterly estimates of the replacement cost of all other assets are obtained by linear interpolation between year-end values. ${ }^{8}$ The resulting estimates of the replacement cost of all assets are shown in column 3 of table 1.

Once the noninterest-bearing liabilities are netted against the corresponding assets, there remains the sum of the net interest-bearing liabilities and equity on the liability side. The market value of these items will be estimated indirectly although direct estimation using actual price quotations for stocks and bonds is entirely feasible in principle. The flow-offunds accounts imply that the debt part of these items is always within a few percent of the gross long-term debt outstanding. Hence, interestbearing financial assets, defined as all liquid assets except demand deposits and currency, plus consumer credit, are about as large as the interest-bearing short-term debt. Assuming the interest rates on short-term assets and liabilities are also similar, net interest paid by nonfinancial corporations can be identified with the interest paid on gross interestbearing long-term debt.

To obtain the market value $(M V D)$ of the principal balances outstanding shown by net interest-bearing liabilities (NIFL), a stream of coupon payments plus the repayment of principal at maturity must somehow be discounted to the present. While the yield on Baa-rated bonds has been used in all previous work for that purpose, inspection of the quality distribution of bonds shown in Moody's Bond Record revealed that the weighted average grade of corporate bonds outstanding is Arated or slightly better. Furthermore, no attempt has been made in previous work to determine the appropriate maturity of long-term debt; rather, discounting has been applied presumptively over various time horizons ranging from five years to infinity. ${ }^{9}$

8. Two successive end-of-quarter values reported in the flow-of-funds accounts are averaged to obtain estimates of financial stocks for any quarter. To obtain quarterly stock estimates from the annual replacement-cost data, one-eighth of the difference between two adjoining year-end values is added to the earlier year-end figure to obtain data for the first succeeding quarter; three-eighths for the second quarter; and so forth.

9. See Economic Report of the President, January 1977, p. 29; Ciccolo, "Four Essays," p. 28; and Tobin and Brainard, "Asset Markets," p. 249. An average maturity of five years is assumed in the Economic Report, Ciccolo assumes an infinite life, Tobin and Brainard adopt a twenty-year term to maturity, and all use the Baa yield in their calculation of $q$. 
To improve on this technique, I took samples consisting of between 162 and 196 A-rated bonds using the prices and amounts of principal outstanding reported in Moody's Bond Record in five months: January 1953, August 1958, July 1964, July 1970, and July 1976. Using the weighted average price of the bonds selected, I then solved for the average maturity that would yield this price, given the coupon rate and the $\mathrm{A}$ yield $(A R)$ for the total nonfinancial corporate sector. The average maturity was thus not calculated directly but inferred as an item reconciling actual market quotations with the present-value formula that is supposed to yield them. To explain the weighted average discount on a mix of bonds, hypothetical maturities must be assumed that are much shorter than the weighted arithmetic average of their actual terms to maturity. ${ }^{10}$ Thus, the hypothetical maturities were found to be only five years in both July 1964 and July 1976, but fifteen years in July 1970 as corporate debt was lengthened greatly in the second half of the sixties and shortened in the first half of the seventies. The hypothetical maturities found for January 1953 and August 1958 were even less than five years, but five years was judged to be a reasonable minimum.

One other matter must be kept in mind in calculating $M V D$. Since net interest paid (INT) - rather than accrued-by nonfinancial corporations is reported at annual rates in the national income accounts, the average annual coupon rate is $I N T$ divided by $N I F L_{-2}$, where the subscript denotes a lag of two quarters since the interest is paid semiannually on almost all bonds. Hence, $M V D$ is calculated by using the formula below with variable maturities cresting at fifteen years in 1970 before coming back down to five years in 1976 in a smooth hump-shaped pattern.

$$
\begin{aligned}
M V D=(I N T / A R)\left(N I F L / N I F L_{-2}\right)[1 & \left.-(1+0.5 A R)^{-2 t}\right] \\
& +N I F L(1+0.5 A R)^{-2 t} .
\end{aligned}
$$

Both NIFL and $M V D$ are reported in table 1.

Estimating the market value of equity is somewhat simpler. Like other studies, this one uses the dividends received from nonfinancial corpora-

10. To illustrate the mathematics of aggregation, the $t$ of a five-year bond and a consol, both with a 6 percent coupon and equal par value, is thirteen years and not infinity when combined to a single issue of the same value if the required yield is 9 percent. Similarly, the weighted arithmetic average maturity of the A-rated bonds in the July 1976 sample was found to be twenty years, compared with a hypothetical average maturity of five years. 
tions divided by the dividend-price ratio of Standard and Poor's 500 stocks for this purpose. However, this method is applied only to dividends paid on common stocks. Preferred stock is treated separately, a distinction that is required because its importance has grown rapidly over the past ten years, particularly in the utility sector, and because the dividend-price ratio on such stock has tended to be twice as high as that for common stocks. According to calculations made with the Compustat tapes, 9 percent of all dividends paid by nonfinancial corporations were paid on preferred stock in 1975, compared with only 4 percent in $1967 .{ }^{11}$

Adding $M V D$ and the preferred-stock and common-stock values shown in columns 6 and 7 of table 1 yields the market value of nonfinancial corporations (column 8 ), which is divided by the replacement cost of their assets (column 3 ). The resulting ratio, $q$, shown in column 9, exceeded unity only during the period 1964:1 through 1966:2 and in two quarters each of 1967 and of 1968. It reached its lowest level since 1952-53 in 1974:4 and then recovered moderately in 1975 and 1976. Even so, $q$ was still lower at the end of 1976 than at any time during the decade 1959-69, and it is obvious that it has fallen substantially in the three quarters since. If $q$ could properly be interpreted as a cardinal variable, it would suggest that the assets of nonfinancial corporations are currently valued in the market at less than 70 cents on the dollar of asset cost.

Such an interpretation is dubious, however, because there are both statistical and conceptual reasons for the equilibrium value of $q$ to be less than one. Estimates by the Bureau of Economic Analysis of the replacement cost of assets may not be entirely suitable for the purpose at hand, since they do not reflect the current cost of putting a given number of efficiency units in place but instead measure the current cost of the same amount of resources as was previously used to produce capital goods; thus "costless" technological progress is ignored. In terms of efficiency

11. Burton G. Malkiel kindly arranged for the dividends on common stock and preferred stock to be aggregated from 1956 through 1975 for corporations in major two-digit industries accounting for about 80 percent of the total dividends paid by nonfinancial corporations. The percentage of common-stock dividends in total dividends was 95.5 in 1956 (also used for 1952-55) and 91.3 in 1975, with 91.0 used in 1976. The percentages obtained for the years $1957-74$ were $95.6,95.5,95.7,95.5$, 95.6, 95.9, 96.1, 96.4, 96.4, 96.3, 95.9, 95.0, 94.5, 94.1, 93.3, 92.4, 92.2, and 91.8, respectively. 
units, even the cost of replacing the net fixed assets entering into the construction of $q$ would be overstated unless the linear depreciation schedule applied by BEA fully compensates for the rise in the efficiency of capital inputs. Furthermore, even if the replacement cost of the net stock of capital is correctly measured, $q$ could be less than 1 for an existing plant in a particular application and location and yet be greater than 1 for new investment in an alternative production process, product line, or location. Since existing facilities are, in fact, rarely replaced with like units in the same location, there is a presumption that the $q$ ratio of existing capital is normally less than 1 .

The investment tax credit provides another reason for expecting $q$ to remain below unity in the long run even for new capital.

In equilibrium, investment will occur up to the point at which

$$
\begin{aligned}
q & =M V / P_{K}=(1-k) \\
& =\sum_{t=1}^{n}(1+r)^{-t}\left\{(1-\delta)^{t-1}(1+p)^{t-1}\left[(1-u)\left(R E V / P_{K}\right)+u a i\right]+u d_{t}\right\},
\end{aligned}
$$

where

$$
\begin{aligned}
& M V=\text { market value of new capital invested in the corporation } \\
& P_{K} \quad=\text { current supply price of capital }(K) \\
& R E V=\text { expected current operating income } \\
& k \quad=\text { the rate of the investment tax credit } \\
& u \quad=\text { income tax rate } \\
& r \quad=\text { financing rate for debt and equity combined } \\
& \delta \quad=\text { constant economic depreciation rate } \\
& d_{t} \quad=\text { variable tax depreciation rate } \\
& a \quad=\text { constant debt-financing percentage } \\
& i \quad=\text { the coupon rate on debt } \\
& p \quad=\text { the expected rate of inflation in prices of output and capital } \\
& \quad \text { goods. }
\end{aligned}
$$

Equation 2 shows that investment qualifying for the credit will be carried to the point at which its market value is the same as its net acquisition cost to business, which is $(1-k)$ per dollar of $K$. Thus the equilibrium level of the marginal $q$ is not only less than one, but falling. As the investment tax credit is raised, the actual value of $q$ is bid up and investment 
is stimulated because the required $q$ has declined. Eventually, however, the actual $q$ will follow the required $q$.

While this matter may be of some consequence to the study of the varying investment response to $q$ of individual firms, it is not a weighty matter in the aggregate. Until 1975, the utility companies were allowed a credit of 4 percent and others 7 percent; the ratio of the investment tax credits claimed to the equipment investment of nonfinancial corporations was between 5 and $5 \frac{1 / 2}{2}$ percent. It was between $9 \frac{1}{2}$ percent and 10 percent thereafter, when firms in general were allowed 10 percent. Since equipment constitutes little more than one-quarter of the net assets in the denominator of $q$, only about a fourth of these rates can be applied. I therefore divide $q$ by ( $1-k$ ), where $k$ is 0.013 from 1962 to 1975 (with an interruption due to the removal of the credit between April 1969 and August 1971) and 0.025 in 1975 and 1976 to reflect the fact that, conceptually at least, the equilibrium value of $q$ can be fixed at one only if $q$ as conventionally measured is divided by $(1-k)$.

Even so, enough data problems remain to advise caution..$^{12}$ It cannot be claimed in any absolute sense that a measured $q$ of less than one will discourage new investment and encourage the purchase of second-hand assets (for instance, through mergers), increased dividend payments, financial investments, and the repurchase of a firm's own liabilities. ${ }^{13}$ Still, one would expect such tendencies to vary inversely to the level of $q$

12. Although the measure of $q$ employed here is more comprehensive than most, a number of corporate assets, such as the value of patents, copyrights, and mineral rights, are still excluded from the denominator. The numerator is also likely to be understated since the use of a stock-price index broader than Standard \& Poor's and the elimination of financial corporations from that index probably lower the dividend-price ratio. Furthermore, except when $q$ is unity, its value depends on the degree of netting applied on the asset and liability sides. Extreme forms of netting, such as netting all financial assets and inventories against the market value of equity and debt, have been suggested by Russell Sheldon, "Some Measurement Issues Connected with Tobin's Financial Model" (Federal Reserve Bank of New York, Research Paper 7624, July 1976; processed), p. 15.

13. Nor can it be argued that a measured value of $q$ that is no greater than unity necessarily proves that capital markets in recent years perceived nonfinancial corporations as having, in the aggregate, no substantial opportunities for intangible growth. For analyses of this issue, see Daniel M. Holland and Stewart C. Myers, "Trends in Corporate Profitability and Capital Costs" (Massachusetts Institute of Technology, Alfred P. Sloan School of Management, WP937-77, May 1977; processed); and Stavros B. Thomadakis, "A Value-Based Test of Profitability and Market Structure," Review of Economics and Statistics, vol. 59 (May 1977), pp. 179-85. 
in securities-valuation models of investment, provided that measurement error in $q$ does not change over time. By allowing for the changing composition of equity, for the investment tax credit, and more important, for the changing hypothetical term to maturity of long-term debt, $I$ have attempted to guard against time-linked errors in the construction of $q$.

\section{Tax Changes and Other Explanatory Variables}

To discover how much $q$ helps in explaining the rate of orders and of gross investment, defined as real orders or investment as a percent of the real gross capital stock of nonfinancial corporations, other explanatory variables must be introduced. First is the Federal Reserve index of capacity utilization in manufacturing $(C U)$ as revised in November 1976. Similar variables have long served on the acceleration-oriented side of the controversy about investment determinants. Since capacity utilization in nonmanufacturing is not closely related to $C U$, taking this variable as a proxy for all capacity utilization is not entirely appropriate. Still, assuming that the desired utilization rate is trendless, a lower level should, on balance, signify reduced willingness to invest in the nonfinancial corporate sector. Since the index has never advanced very rapidly in peacetime, a low current $C U$ foretells a below-average rate for some quarters to come, making additions to capacity less pressing. On the other hand, its current level should affect the expected profitability of only the most short-lived new investments so that its interaction with variables influencing the expected rate of return should be small.

Among the rate-of-return variables, inflation and tax factors stand out if the effect of all financial variables such as interest rates is assigned to $q$. First, a surge in the prices of inputs traded in auction markets has two types of effects. It encourages nonfinancial corporations to order before increases in the costs of raw materials are reflected in the prices of capital goods. Second, it increases the real tax burden because three-quarters of the cost of inventories used up is still calculated on the FIFO basis by nonfinancial corporations, according to preliminary estimates for 1976 from the Bureau of Economic Analysis. Since changes in the inflation rate are promptly reflected in the (negative) inventory valuation adjustment (IVA), the expected sign on IVA is ambiguous. If inflation is expected to continue at a high rate, the desired stock of capital would be 
reduced on account of the tax increase induced under historical-cost accounting. In that case the coefficient on $I V A$ should be positive. However, if the price bulge is held to be temporary, the desire to beat it through stepped-up ordering may win out.

There is no similar doubt about the expected long-term effects of higher underlying rates of inflation. A higher rate of inflation raises the percentage shortfall of historical-cost depreciation from replacement-cost depreciation over an entire replacement cycle. The extent to which the resulting tax increase is offset by the deductibility of the inflation premium in interest rates depends on the degree to which assets are debt financed. ${ }^{14}$ Furthermore, inflation also directly hurts capital-goods producers, who generally operate in customer rather than auction markets, if the markups traditionally applied are based more nearly on the historical cost than on the replacement cost of inputs. ${ }^{15}$

Three variables are therefore needed to capture the implicit tax effects of inflation: (1) the IVA, (2) the adjustment of capital consumption allowances with consistent accounting from historical cost to current replacement cost, $I C C A,{ }^{16}$ and (3) the ratio of debt to assets, $D / A$. For

14. Detailed discussions are contained in Henry J. Aaron, ed., Inflation and the Income Tax (Brookings Institution, 1976), pp. 33-120; John B. Shoven and Jeremy I. Bulow, "Inflation Accounting and Nonfinancial Corporate Profits: Financial Assets and Liabilities," BPEA, 1:1976, pp. 15-57; and George M. von Furstenberg and Burton G. Malkiel, "Financial Analysis in an Inflationary Environment," Journal of Finance, vol. 32 (May 1977), pp. 575-88.

15. Transitory investment stimuli may be generated by inflation because the nominal cost of capital is slow to adjust, according to Dale W. Jorgenson and Calvin D. Siebert, "Optimal Capital Accumulation and Corporate Investment Behavior," Journal of Political Economy, vol. 76 (November/December 1968), pp. 1123-51, especially pp. 1126 and 1143. Tobin's $q$ theory does not demonstrate how inflation might affect the market value of firms relative to the replacement cost of their assets. By contrast, Okun views markup onto historical costs rather than replacement costs as part of the rules followed to safeguard established customer-supplier relationships in nonauction-type markets. In that case a rise in the rate of inflation to a new level would cause the real value of equity to decline though existing leverage would be a countervailing factor until the average interest rate on all outstanding debt has fully adjusted to the higher inflation rate. See Arthur M. Okun, "Inflation: Its Mechanics and Welfare Costs," BPEA, 2:1975, pp. 351-90.

16. The capital consumption adjustment $(C C A)$ reported quarterly for nonfinancial corporations is decomposed annually by BEA into that part of the difference between historical-cost accelerated tax depreciation and replacement-cost straight-line depreciation that is due to (1) differences in the depreciation methods and service lives applied to historical-cost data $(R C C A)$, and (2) inflation in the prices of depreciable assets $(I C C A)$. Quarterly data for the latter were estimated by 
proper scaling in regressions of the rates of capital-goods orders and investment, the first two terms are expressed in percent of the nominal gross stock of nonresidential fixed capital. The last term is obtained by dividing the market value of debt in column 5 of table 1 by the replacement cost of net assets in column 3. Normally, the fraction of the total return on assets that is tax deductible can be expected to rise monotonically with the debt-asset ratio and so can the redistribution from existing bondholders to equity holders that occurs when interest rates rise because of unexpected inflation.

It is probably realistic to treat the effects of inflation on taxes as unanticipated or as akin to those of temporary changes in taxes themselves. Since the highest rates of inflation were experienced toward the end of the 1952-76 data period, the capital stock has had little time to adjust even if the expected rate of inflation has risen in recent years. However, this assumption cannot be extended to permanent changes in explicit taxes imposed by statute, to which the capital stock will adjust barring offsetting changes in the gross rate of return on capital through induced cost increases or margin reductions of the kind discussed in the literature on short-term shifting of the corporation income tax. ${ }^{17}$ Specifically, the investment rate will be raised for a time by permanent increases in the investment tax credit, permanent cuts in corporate tax rates, ${ }^{18}$ and permanent liberalization of depreciation provisions. In neoclassical formulations the resulting capital deepening tends to reduce the gross rate of return on capital until equilibrium between that rate and the rental cost of capital is restored. In the long run, the rates of both net and gross investment would be unchanged although the amounts of both must be perma-

distributing quarterly the differences in $R C C A$, which move quite steadily between statutory changes, and then solving for $I C C A$ using the identity $I C C A=C C A$ $-R C C A$. Changes in $R C C A$ that are due to permanent changes in depreciation rules were used to construct one of the explicit tax-change variables.

17. For references and an evaluation see Joseph A. Pechman, Federal Tax Policy (3rd ed., Brookings Institution, 1977), pp. 129-36.

18. In their article, "Application of the Theory of Optimum Capital Accumulation," in Gary Fromm, ed., Tax Incentives and Capital Spending (Brookings Institution, 1971), pp. 16-17, 53, Robert E. Hall and Dale W. Jorgenson have suggested that a cut in the corporate rate will increase the user cost of capital and depress investment by driving up the required gross marginal product of capital if economic depreciation is below depreciation for tax purposes as it was during most of the sixties. However, this deduction was based on restrictive assumptions that are not adopted here, 
nently higher if a higher capital-output ratio is to be maintained in a growing economy.

A phaseout pattern must be applied to all major permanent changes in taxes to represent this process when the gross investment rate (100 times the real nonresidential gross investment divided by the real gross fixed nonresidential stock of capital of nonfinancial corporations) is used as the dependent variable, as in John Ciccolo's estimates of the effect of $q$. In other words, following any change in tax laws, the resulting change in federal profits-tax liabilities, again expressed in percent of the gross capital stock, must be multiplied by a factor that declines from unity at the time of introduction to zero over a period of years as the adjustment of the capital stock is completed. The phaseout pattern is dictated by the following consideration: the greater the initial change in the after-tax rate of return on capital, the greater the desired investment response. However, decision lags and delivery lags prevent an immediate strong response of investment. As time elapses, the more investment reacts, the lower the change in the after-tax rate of return remaining from prior tax actions and hence the lower the incentive to respond further.

Instead of searching for the phaseout patterns that happen to yield the best-fitting permanent tax-change variables in the orders and investment equations, I decided to rely on findings by others and on the thrust of neoclassical theory for independent information on the proper phaseout pattern. Neoclassical investment models have often been predicated on the assumption that the before-tax discount rate is stationary because the burden of any tax on capital is borne by that factor of production in both the short and the long run. ${ }^{19}$ Hence, any general cut in taxes on capital should raise the after-tax rate of return. However, since the corporation income tax applies to only about one-third of net privately owned fixed capital, the rise in the after-tax rate of return will be far greater in the short run than in the long run when the risk-adjusted, aftertax rates of return have been equalized on capital employed in all sectors. The effective tax rate on the return on capital has, in fact, declined almost

19. See ibid., pp. 16-18, and Peter M. Miezkowski, "On the Theory of Tax Incidence," Journal of Political Economy, vol. 75 (June 1967), pp. 250-62. The assumption of a constant before-tax discount rate may, however, be untenable in models requiring an increase in aggregate investment and not just a shift of investment activity between different sectors. See Paul Taubman and Terence J. Wales, "Impact of Investment Subsidies in a Neoclassical Growth Model," Review of Eco. nomics and Statistics, vol. 51 (August 1969), pp. 287-97. 
continuously during the post-Korean period, ${ }^{20}$ so that a gradual rise in the equilibrium level of the after-tax rate of return may well be expected. ${ }^{21}$ The phaseout pattern then determines how fast the actual rate is expected to return to its moving-equilibrium level after any permanent tax change.

To see which phaseout pattern is consistent with the behavior of the after-tax rate of return $(A T R)$ on net capital (including inventories and land), that variable was regressed on $C U$, on the change in the unemployment rate from the preceding quarter, on time, on the inflation-tax changes involving $I V A, I C C A$, and $D / A$, and on the sum of all the variables reflecting statutory tax changes. Two different phaseout patterns were applied to all permanent tax changes, one assuming that the adjustment of the capital stock to permanent tax changes is substantially completed within five years, and the other assuming that it takes seven years. Since around 98 percent of the total variation in $A T R$ could be accounted for with autoregressive least squares in both cases, there was little to choose between the two. However, since the evidence provided by others favors the faster phaseout pattern, ${ }^{22}$ I decided to use the variables constructed with that pattern in the investment and orders equations. This choice would not be inconsistent with the behavior of $A T R$ if the investment response to permanent tax reductions is found to peak when, or just before, that rate recedes most rapidly from its elevated level, about two years after any change. Runs with either type of phaseout pattern and an analysis of the overall regression results on $A T R$ are provided in the appendix.

As reported there, the total tax-change variable used in the equation

20. The effective tax rate, defined as the ratio of accruals of corporate profits tax to the sum of NIA profits and net interest paid by nonfinancial corporations, declined from 50.8 percent in 1955 to 41.0 percent in 1976 , with most of the decline occurring between 1955 and 1962. All three years named in this comparison follow a respective reference-cycle trough by one year. While the effective tax rate shot up to 48.1 percent in 1974 on account of the rise in taxable inventory profits, the normal level has remained far below that of the fifties.

21. Unless, of course, the required risk premiums drop by the same proportion. See William D. Nordhaus, "The Falling Share of Profits," BPEA, 1:1974, pp. 169208. On the other hand, the finding by Feldstein and Summers that the cyclically adjusted before-tax rate of return on the capital employed by nonfinancial corporations is trendless implies a rise in the after-tax rate of return if similarly adjusted. See "Is the Rate of Profit Falling?" pp. 217-21.

22. See Robert E. Hall, "Investment, Interest Rates, and the Effects of Stabilization Policies," BPEA, 1:1977, pp. 61-103; and Hall and Jorgenson, "Application of the Theory of Optimum Capital Accumulation," p. 41. 
for the after-tax rate of return on capital is simply the sum of the phased permanent changes due to changes in rates, in the investment tax credit or in depreciation provisions, and of temporary rate changes. Since the expected effect of each of these measures on capital-goods orders and shipments may not be proportional to the change in federal tax receipts involved, each of them will be tested separately in the orders and investment equations. No phaseout factor is applied to temporary rate changes so that the numerator is always equal to the estimated change in the federal profits-tax liabilities of nonfinancial corporations. While temporary tax changes have the same initial impact on the actual after-tax rate of return and on cash flow as do permanent changes, they leave the profitability of most plannned investments untouched. However, brief suspensions of the investment tax credit, such as that from October 1966 to March 1967 , can modify the quarterly pattern of orders both during and after the suspension period. This calls for the introduction of a dummy variable, IC66, which is negative during the suspension period and positive for a few quarters thereafter. ${ }^{23}$ All other tax-change variables are signed by the change in federal tax receipts they produce, with tax cuts negative and increases positive. Throughout this paper, tax-change variables, $I V A$, and ICCA, which are originally in current dollars, are scaled by the current-dollar equivalent of the divisor used to construct the dependent variable in any run, and expressed in percent.

\section{The Lag from New Orders to Shipments of Capital Goods}

As the appendix demonstrates, variations in the actual after-tax rate of return on the net capital employed by nonfinancial corporations are linked to the cyclical variables, capacity utilization and the change in the unemployment rate, and to the implicit (inflation-related) and explicit tax-change variables. But how in turn do these variables influence new orders of plant and equipment? Any of them must affect orders before they can affect investment. Furthermore, since shipments lag significantly

23. The value of the dummy was set equal to -0.9 in both $1966: 4$ and $1967: 1$ since the suspension covered only about 0.9 of the first quarter and even less of the second. The sign of the dummy was then reversed. To allow the orders deferred during the suspension period to be made up completely within a year, the dummy was set at $0.8,0.5,0.3$, and 0.2 , respectively, in the ensuing four quarters. 
behind orders, the analysis of orders should yield useful insights into the lag structures appropriate for investment.

Unfortunately, the statistics on orders are not entirely suitable for predicting the investment of nonfinancial corporations. Neither of the two "nondefense" series, "contracts and orders for plant and equipment" and "value of manufacturers' new orders, capital goods industries" (which refers to equipment ordered from capital-goods manufacturers), is available for nonfinancial corporations alone. Nonfinancial corporations account for around 70 percent of total nonresidential fixed investment. Although they probably generate a similar percentage of all domestic orders for plant and equipment, the exact figure is not known and may oscillate procyclically. The two orders series are both now available in current and in 1972 dollars so that an implicit deflator can be calculated. ${ }^{24}$ According to this deflator, the price of orders, relative to the price of nonresidential fixed investment, rose continuously, by over 18 percent, from 1952 to 1976. Another problem is that even after revisions in the statistics on unfilled orders and new orders, the Bureau of the Census concluded that "a statistically reliable level [of unfilled orders] is still not known." 25

In spite of these data problems, an analysis of the distributed lag from new orders to shipments is indispensable to deriving lag structures for the equations on capital-goods orders and investment that are mutually consistent. As described by Joel Popkin, ${ }^{26}$ shipments of capital goods $(S)$ follow new orders $(O E)$ with a flexible lag that is likely to depend on the ratio of unfilled orders to shipments $(U / S) .{ }^{27}$ When that ratio

24. The historical series are shown in Business Conditions Digest (April 1977), pp. 96-97. Contracts and orders for plant and equipment are the sum of (1) the value of commercial and industrial contracts, (2) the value of privately owned public works and utilities contracts, and (3) the value of manufacturers' new orders, in nondefense capital-goods industries. The constant-dollar series on the third component is shown for the first time. Foreign orders and orders for export are included in both quarterly series.

25. U.S. Bureau of the Census, Current Industrial Reports, M3-1.6, "Manufacturers' Shipments, Inventories, and Orders: 1958-1976 (Revised)" (GPO 1976), p. iv. The estimates of unfilled orders and new orders were revised by over 40 percent and by 5 percent, respectively, for 1975 .

26. Joel Popkin, "The Relationship Between New Orders and Shipments: An Analysis of the Machinery and Equipment Industries," Survey of Current Business, vol. 45 (March 1965), pp. 24-32.

27. The market category, "capital goods industries," now includes machinery except electrical (excluding farm machinery and equipment and machine shops), 
is relatively high, it takes longer to fill new orders so that the influence of recent orders on current shipments will be weaker and that of older orders stronger. However, all new orders not cancelled are supposed to lead to shipments within a fixed number of quarters. ${ }^{28}$ Popkin assumed that all orders placed in any one quarter and not shipped in the next quarter are shipped in the quarter thereafter, so that the weight of new orders on shipments can shift only between two quarters. However, since the 1976 revisions raised the mean of $U / S$ from between 1 and 2 to 2.35 , if the value of quarterly shipments is used in the denominator, the lag of shipments on orders must be four rather than two quarters. Furthermore, the combination of new orders, unfilled orders, and shipments is available only in current dollars and, back to 1958, only for the market category "capital goods-total"- -that is, for defense and nondefense capital goods combined. To prevent the ratio of unfilled orders to shipments from being distorted by inflation, it was constructed by dividing the unfilled orders at the end of any quarter by the nominal shipments in the succeeding quarter on the theory that unfilled orders reflect the prices realized on subsequent shipments.

The extension of Popkin's flexible lag process to four quarters yields the following structural specification:

$$
\begin{aligned}
S_{t}=\left[b_{0}+b_{1}(U / S)_{t-1}\right] O E_{t-1}+\left[b_{2}+b_{3}(U / S)_{t-2}\right] O E_{t-2} \\
+\left[b_{4}+b_{5}(U / S)_{t-3}\right] O E_{t-3}+\left[b_{6}+b_{7}(U / S)_{t-4}\right] O E_{t-4}
\end{aligned}
$$

The constraint that all orders received in period $t-4$ will have been filled by the end of period $t$ provides a substitute for the last term in the previous equation:

(4) $\left[b_{6}+b_{7}(U / S)_{t-4}\right] O E_{t-4}=$

$$
\left[a-\left(b_{4}+b_{5}(U / S)_{t-4}\right)-\left(b_{2}+b_{3}(U / S)_{t-4}\right)-\left(b_{0}+b_{1}(U / S)_{t-4}\right)\right] O E_{t-4} .
$$

electrical machinery (except household appliances and electronic components), and shipbuilding and military tank vehicles, railroad equipment, communication equipment, aircraft and aircraft parts and ordnance. See "Manufacturers' Shipments, Inventories, and Orders: 1958-1976," p. xiii, for identification of the defense and nondefense components available separately since 1968.

28. New orders are derived by adding the change in unfilled orders between the current and previous months to the estimate of shipments for the current month, so that new orders are reported net of cancellations. The lag structure has some noise since cancellations received this period are applied against this period's orders regardless of whether they refer to them or to orders received earlier. 
Unless there are unexplained level differences or data inconsistencies between the orders and shipments series, the coefficient $a$ would have to be unity since new orders are reported net of cancellations. Substituting and combining terms then yields the estimating equation:

$$
\begin{aligned}
S_{t}= & b_{1} \Delta(O E \cdot U / S)_{t-1}+\left(b_{1}+b_{3}\right) \Delta(O E \cdot U / S)_{t-2} \\
& +\left(b_{1}+b_{3}+b_{5}\right) \Delta(O E \cdot U / S)_{t-3}+b_{0} \Delta O E_{t-1}+\left(b_{0}+b_{2}\right) \Delta O E_{t-2} \\
& +\left(b_{0}+b_{2}+b_{4}\right) \Delta O E_{t-3}+a O E_{t-4}
\end{aligned}
$$

where a subscript of $t-i$ on differenced variables indicates the change from quarter $t-(i+1)$ to quarter $t-i$. The variable $U / S$ is entered in mean deviants by subtracting 2.35 from the ratios originally constructed. With this modification the expected size of $b_{0}, b_{2}$, and $b_{4}$ is easily explained: all of these coefficients must be positive. Furthermore, they must sum to less than unity if part of new orders results in shipments only with a four-quarter lag so that $b_{6}$, the complement of the sum of $b_{0}, b_{2}$, and $b_{4}$, is positive also.

The signs of $b_{1}, b_{3}, b_{5}$, and $b_{7}$ are less easily explained because a change in $U / S$ redistributes the weights of orders received at different times in current shipments. Clearly, the higher $U / S$, the less recent orders will matter. Hence $b_{1}$ must be negative and $b_{7}$ positive. The coefficients $b_{3}$ and $b_{5}$ both apply to terms around the middle of the lag distribution. How a rise in $U / S$ affects their weight cannot be determined a priori, since there is both redistribution "in" from the short side of the lag domain and redistribution "out" from the far side as weights shift contiguously. Though matters are somewhat complicated through the multiplication of $U / S$ by $O E$, the sum of $b_{1}, b_{3}, b_{5}$, and $b_{7}$ must be zero under stationary conditions if the redistribution among periods remains confined to four quarters.

Estimation of equation 5 yielded the following results (in which the numbers in parentheses are $t$ statistics):

$$
\begin{aligned}
S_{t}= & -0.525 \Delta(O E \cdot U / S)_{t-1}-0.301 \Delta(O E \cdot U / S)_{t-2} \\
& (-8.55) \quad(-4.54) \\
& -0.181 \Delta(O E \cdot U / S)_{t-3}+0.201 \Delta O E_{t-1}+0.643 \Delta O E_{t-2} \\
& (-3.40) \quad(4.34) \quad(11.20) \\
& +0.926 \Delta O E_{t-3}+1.000 O E_{t-4} \\
& (24.24) \quad(306.95) \\
\bar{R}^{2}= & 0.995 ; \text { Durbin-Watson }=1.64 .
\end{aligned}
$$


These regression results conform to expectations in every detail, and do not display significant serial correlation in the error terms. The structural coefficients obtained from the regression and shown below indicate that when $U / S$ is at its mean, 20 percent of the new orders received last quarter are filled this quarter, as are 44 percent of the orders received two quarters ago, 28 percent of those received three quarters ago, and 7 to 8 percent of those received four quarters ago. However, if $U / S$ is above the mean, the weight on current shipments of the most recent orders, received last quarter, is reduced in favor of all the more distant quarters, as only $b_{1}$ is found to be negative. ${ }^{29}$

\begin{tabular}{|c|c|}
\hline \multicolumn{2}{|c|}{ Structural coefficients } \\
\hline$b_{0} \quad 0.201$ & $b_{5} \quad 0.120$ \\
\hline$b_{1}-0.525$ & $\begin{array}{lll}b_{6} & 0.074\end{array}$ \\
\hline$b_{2} \quad 0.442$ & $b_{7} 0.181$ \\
\hline 0.224 & $\begin{array}{ll}a & 1.000\end{array}$ \\
\hline 0.283 & \\
\hline
\end{tabular}

What do these results say about how the lags in investment equations must relate to the length of lags in the orders equations? The coefficients with even-numbered subscripts, $b_{0}$ through $b_{6}$, sum to unity by assumption. If this assumption is false because the maximum length of lags is either significantly shorter or longer than four quarters, the magnitude assigned to $b_{6}$ would either be very small or negative, or implausibly large. Neither is the case since all but 7 to 8 percent of the new orders for equipment were estimated to result in shipments within three quarters after the quarter in which the orders were placed. It seems entirely reasonable to assign that remainder to the fourth quarter. Furthermore, the coefficient $a$ was estimated to be unity (0.9997). It would have been less than unity if new orders lead to shipments with longer lags than four quarters since the values for both nominal orders and shipment are rising over time; and it would have been greater than unity in the opposite case. ${ }^{30}$ Hence the initial specification has been vindicated in every respect. Whatever lags

29. The structural coefficients are obtained from the regression coefficients of text equation $5 \mathrm{a}$, using the conditions $b_{0}+b_{2}+b_{4}+b_{6}=1$ and $b_{1}+b_{3}+b_{5}+b_{7}$ $=0$.

30. Conversely, if the "true" lag is distributed over four quarters but the specification allowed for three (five) quarters, $a$ should be less (greater) than unity. This expectation was confirmed by the data since the estimated value of $a$ was 0.997 with three quarters and 1.004 with five quarters. 
are found to apply to explanatory variables in the orders equations must be lengthened by four quarters in the investment equations to account for the distributed lag from new orders to shipments.

Since this finding applies strictly only to equipment, longer lags cannot be ruled out when the rate of total nonresidential investment, rather than of equipment alone, is analyzed, as Ciccolo has done. It is obvious that new plant construction can take several years, particularly in the utility sector. Since utility investment is also rather special in other respects, the attempt to deduce the lag structure of investment determinants from the behavior of orders clearly does not fit every sector or every type of investment. However, it may fit the part that makes for the greatest variations in the gross nonresidential investment rate-that is, equipment investment. The answer to whether it does lies in the coherence of the regression results on the rates of new orders and investment with and without the use of $q$ reported in the remainder of this paper. But, first, how does $q$ function in simple regressions and how does it interact with other variables in multiple regressions with adjustment for first-order autocorrelation of the error terms?

\section{The Information Content of $q$}

As an extreme position, it could be argued that $q$ embodies all the information relevant to corporate orders for capital goods and investment decisions. Thus, one of Ciccolo's specifications reflects the view that investment rates can be explained solely by $q$ and the inverse of the real stock of gross fixed capital with adjustment for first-order autocorrelation of the residuals. ${ }^{31}$ Since the inverse of the capital stock with a negative coefficient accounts merely for the persistent updrift in the ratio of gross fixed investment to the gross capital stock that is due to the growing importance of equipment in total capital compared to longer-lived struc-

31. See Ciccolo, "Four Essays," pp. 40-42, equation I, also shown by Barry Bosworth, "The Stock Market and the Economy," $B P E A, 2: 1975$, p. 287. Lags actually reported in the literature on direct tests of $q$ in investment equations range from eight to thirteen quarters. For the former, see Ciccolo. The latter is included in a comparison of models appearing in Robert F. Engle and Duncan K. Foley, "An Asset Price Model of Aggregate Investment," International Economic Review, vol. 16 (October 1975), pp. 642-43. 
tures, $q$ is the only variable that can explain short-term fluctuations in the investment rate in such equations. The assumption is that if $q$ is below equilibrium good stewardship will make corporate managers allocate less after-tax earnings and external funds to fixed investment: since the opportunity cost of a dollar so invested is higher than the market value of a dollar's worth of new producers' durables installed in the firm, stockholders would gain if managers curtailed fixed investments as long as $q$ remains low.

An opposing view could start out simply by suggesting that stockholders and the evaluations on Wall Street may not rule supreme and that the planning horizons, incentives, and perceptions of corporate managers and financial investors in the corporation need not coincide. This view can be held without asserting an inherent difference in the interests of managers and investors. Managers acting in what they perceive to be the best longrun interests of shareholders and the corporation may still not pay much attention to current and past average levels of $q$, especially if they are convinced that the marginal $q$ exceeds the average $q$ so that increasing some types of fixed investment raises the expected level of $q$. Whether $q$ can go it alone or whether other factors matter also-or, indeed, whether some of these other factors explain much of the variation in $q$ and, moreover, influence the investment rate beyond the extent that they influence $q$ in the first place-thus remains an empirical question.

As part of the answer to these questions, the results of the preliminary investigations reported in table 2 show that using only $q$ and a capitalstock-mix variable equal to the ratio of the real gross stock of equipment to that of plant and equipment, $G E / G P E$, indeed explains a large part of the variance in the annualized orders and investment rates. ${ }^{32}$ The ratio $G E / G P E$, which rises from 0.40 in 1952 to 0.52 in 1976 with a mean of 0.4672 , is used without lags in lieu of Ciccolo's inverse of the capital stock, and its expected coefficient is positive. The expected size of the coefficient of $G E / G P E$ is between 6 and 7 in the investment equations

32. So far, only annual data are available from the Bureau of Economic Analysis for nonfinancial corporations. The constant-dollar investment of nonfinancial corporations was distributed quarterly by assuming that their share of the total nonresidential investment reported quarterly by BEA was constant throughout the year. Quarterly data on "contracts and orders for plant and equipment in 1972 dollars" are provided as series 20 in the Business Conditions Digest, and the denominator used to construct the orders rate was the same as that used for investment. 


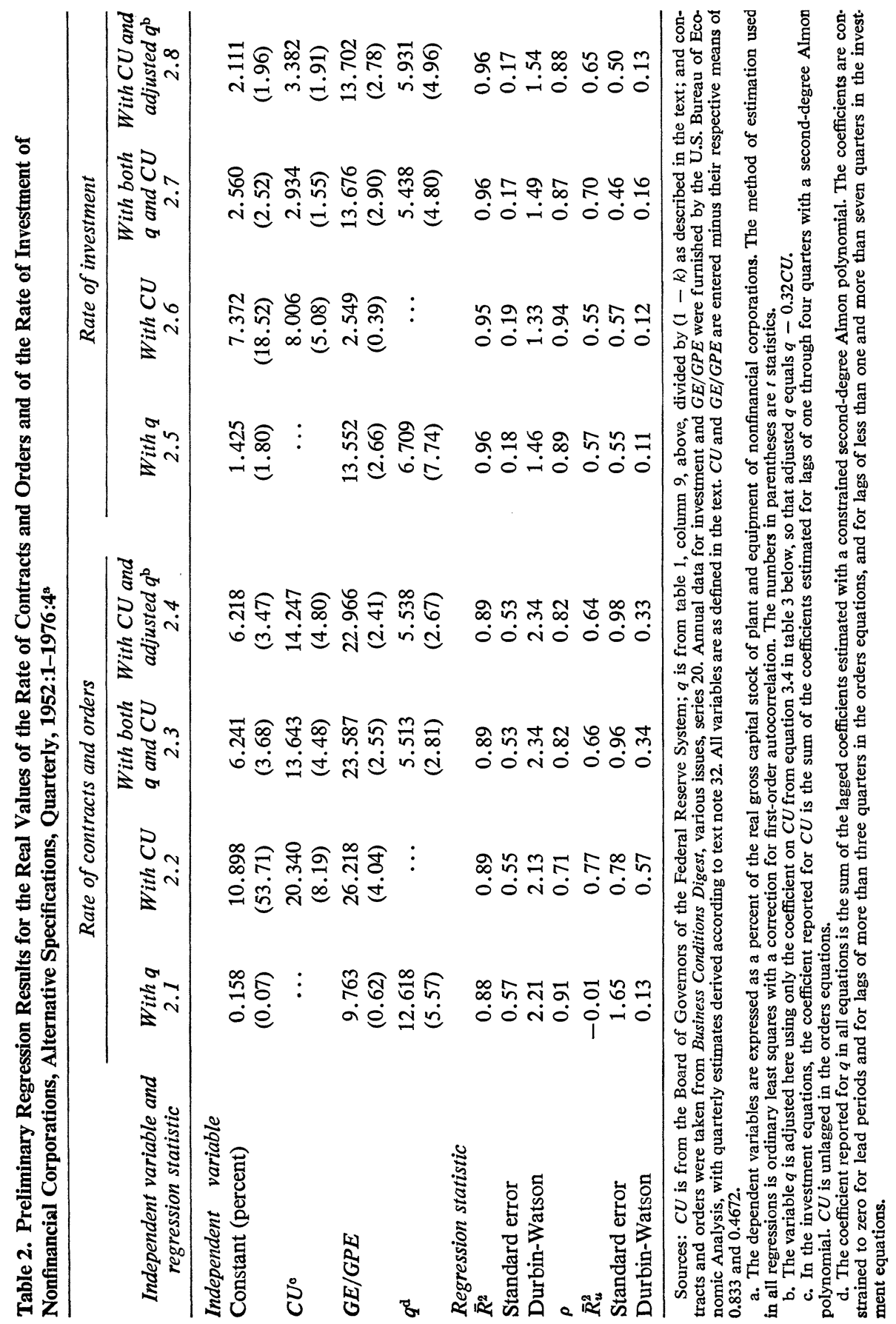


and around 10 in the orders equations since the mean of the annualized orders rate is 11.0 percent compared with a mean of 7.5 percent for the investment rate. ${ }^{33}$ In equations 2.1 and 2.5 of table $2, \mathrm{I}$ have used this variable and a second-degree Almon lag on $q$ whose coefficients are constrained to zero for lead periods and for lags of more than three quarters in the orders equation, and for lags of less than one and more than seven quarters in the investment equation to reflect the application of the estimated lag from orders to shipments; the $\bar{R}^{2}$ estimated with AOLS is 88 percent and 96 percent, respectively. However, at least in the orders equation, equal or better results can be obtained when the capacity utilization rate is substituted for $q$. Thus, the results of monocausal regressions with $q$ can easily be matched by equally simple regressions with $C U$. In fact, $C U$ worked best without lags in the orders equation and with lags of one to four quarters in the investment equation, and serial correlation was a smaller problem than in the equation with $q$.

Serial correlation of the error term is most debilitating in the orders equation with $q$ and the capital-mix variable alone. To see this, compare

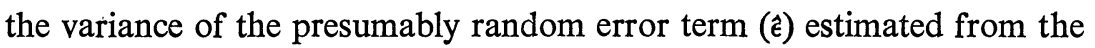
AOLS regressions, to the mean-square of the difference, $u$, between the actual value of the dependent variable, $y$, and its value estimated with all coefficients other than $\rho$ found in the AOLS regression, $\sum_{i} \hat{\beta}_{i} x_{i}$. The term $u$ is defined by the first-order Markov process, $u_{t}=\hat{\rho} u_{t-1}+\hat{\epsilon}_{t}$, which immediately shows that the expected value of $u$ is zero if the expected value of $\hat{\epsilon}$ is zero, since $E(u)=E(\hat{\epsilon}) /(1-\hat{\rho})$. Hence the expected population value of the mean square of $u$ is the variance $\sigma_{u}^{2}$ if the number of observations is large. Furthermore, defining $R_{u}^{2}=1-\left(\sigma_{u}^{2} / \sigma_{y}^{2}\right)$, and $R^{2}=1-\left(\sigma_{\hat{\epsilon}}^{2} / \sigma_{y}^{2}\right)$, and

33. The average age of the gross stock of equipment in 1972 dollars, estimated as around seven years since 1960 , is 40 to 50 percent of the average age of structures. In a stationary setting one could infer from this that equipment is replaced at most $2 \frac{1}{2}$ times as often as structures. A 0.01 rise in $G E / G P E$ (from a level of 0.47 ) would then raise the discard rate by 0.88 percent of itself, or by 0.035 from its mean of 3.94 (percent of the real gross stock of nonresidential fixed capital of nonfinancial corporations). In the absence of growth, the coefficient on $G E / G P E$ would thus be expected to be 3.5. However, in a growing economy, differences in the average age of different types of capital understate the differences in their turnover rates. Thus, the annual discard rates estimated from BEA data increased from 3.52 in 1952 to 4.28 in 1976 , or by almost twice as much as the $0.42(3.5 \times 0.12)$ rise expected under stationary conditions. Thus, the coefficient on GE/GPE should be between 6 and 7 . Direct use of the discard rates (with quarterly interpolation) in lieu of the capitalmix variable in the investment equations proved unrewarding. 
using $\sigma_{u}^{2}=\sigma_{\hat{\epsilon}}^{2} /\left(1-\rho^{2}\right)$, Green and Watson ${ }^{34}$ have shown that the expected asymptotic relation of $R_{u}^{2}, R^{2}$, and $\rho^{2}$ is

$$
R_{u}^{2}=\left(R^{2}-\rho^{2}\right) /\left(1-\rho^{2}\right) \geq 0, \rho<1 .
$$

Though the estimated value of $\bar{R}_{u}^{2}$ will normally fall below the expected value given by equation 6 , very large differences between the two coefficients of determination indicate inconsistent estimation, at least in the logical sense. ${ }^{35}$

Such large differences arise in equation 2.1, where $\bar{R}_{u}^{2}$ is found to be negative for the orders rate. This implies that the coefficients of $q$ found in that equation point the wrong way when given a ceteris paribus interpretation. Since, instead of explaining the investment and orders rates directly, variations in $q$ merely generate estimates with highly autocorrelated error terms explained by $\rho$, nothing is learned about how $q$ might function outside this error band. This would inhibit out-of-sample forecasting applications if they were made for more than a few quarters ahead even if future levels of $q$ were known with certainty. ${ }^{36}$

Hence one must either abandon the AOLS method of estimation or add those omitted variables that may account for inconsistency to simple AOLS

34. R. Jeffery Green and Harry S. Watson, "What Do Autoregressive Least Squares Results in Financial Analysis Really Mean?" (Indiana University, n.d.; processed).

35. In an equation of the form $y_{t}=\sum_{i} \beta_{i} x_{i t}+\rho u_{t-1}+\epsilon_{t}, \bar{R}_{u}^{2}$ must be nonnegative if the $\beta_{i}$ are true population estimates or known constants. When $\rho^{2}$ approaches $\bar{R}^{2}, R_{u}^{2}$ approaches zero in the Green-Watson formula, and almost the entire explanatory power of AOLS regressions derives from the explanation of the variance of $u_{t}$ through the first-order Markov process. If the Green-Watson formula is very far from being satisfied in a sample there is a presumption of specification error due to the omission of relevant variables, although significance levels of the difference between the expected $R_{u}^{2}$ and the estimated $\bar{R}_{u}^{2}$ have not yet been derived. In equation 2.5 in table 2 , the expected value of $\bar{R}_{u}^{2}$ is 0.81 , compared with the estimated sample value of 0.57 . The difference between the expected and estimated values of $\bar{R}_{u}^{2}$ is much greater if Ciccolo's equation is replicated directly; $\bar{R}_{u}^{2}$ is then again negative $(-2.35)$ even though the estimated $\tilde{R}^{2}(0.96)$ exceeds the estimated value of $\rho^{2}(0.90)$. While the sample mean, as opposed to the expected value, of $u_{t} \equiv y_{t}-\sum_{i} \hat{\beta}_{i} x_{i t}$ need not be precisely zero (this point is owed to Tobin), so that the estimated ${ }^{i} \tilde{R}_{u}^{2}$ would normally fall below the expected $\bar{R}_{u}^{2}$, this fact alone does not account for the enormous deficit $(-2.95)$ between these two coefficients found in this case. With $u$ adjusted to shift $\bar{u}$ from 0.93 to 0 , this alternative $\vec{R}_{u}^{2}$ is still negative $(-1.01)$.

36. A short-term forecasting application is reported in James Tobin, "Monetary Policy in 1974 and Beyond," BPEA, 1:1974, p. 225. The $q$ ratio was kept at its 1973:4 actual level throughout the forecast period of the following year. 
estimates with $q$. The latter approach is reflected in equations 2.3 and 2.7 of table 2, which show that including both $C U$ and $q$ restores $\bar{R}_{u}^{2}$ to the more respectable size of 0.70 , compared with 0.84 expected from the GreenWatson formula. However, the results also suggest that $q$ is functionally related to $C U$ so that the overall explanatory power improves very little and the size and significance of the regression coefficients suffer when $q$ is added to the run with $C U .{ }^{37}$

To obtain estimates that separate the effects of all other "independent" variables without going through $q$, more is therefore required than the mere addition of explanatory variables to equations with $q$. Rather, all the nonfinancial factors that were previously discussed as candidates for entry into the orders and investment equations must be examined for their influence on $q$. If they are significant in explaining variations in $q$, the estimates can then be used to adjust $q$ to make the residual variations in it independent of the other explanatory variables in the regression and vice versa. Were it not for the presence of variables with Almon lags and for the fact that the tax variables are scaled differently in the equations for $q$ from the orders and investment equations, this procedure would bring no new information to the regression and would not change the size or significance of the coefficient of $q$ or the size of $\bar{R}^{2}$. Even then, however, it would change both the size and significance of the other regression coefficients compared with what they were in equations 2.3 and 2.7. Adjusting $q$ thus allows a direct reading from the regression results of what these other variables are doing when their influence is not partly conveyed through $q$. Indeed, comparing equations 2.3 and 2.4 shows that merely adjusting or standardizing $q$ for the influence of $C U$ yields some marginal improvements in the significance of $C U$ without altering the significance of $q$. However, the adjustments must be carried further.

\section{DECODING $q$}

Barry Bosworth has written that "the securities-valuation model leaves the basic determinants of investment in a black box." ${ }^{38}$ While the use of $q$ "offers the advantage of not requiring the explicit measurement of the

37. The zero-order correlation coefficient between $C U$ and $q$ is 0.40 .

38. Bosworth, "Stock Market and the Economy," p. 286. 
effect of taxes, expected output, and expected prices needed in the neoclassical version," ${ }^{39}$ no one has shown empirically how movements of $q$ in the aggregate can be explained for the nonfinancial corporate sector as a whole. ${ }^{40}$ Unless one knows with some precision the factors influencing $q$, there is no way to judge how changes in $q$ should affect capital-goods orders and investment and how such changes should enter the estimating equations. Furthermore, if $q$ cannot readily be forecast, investment equations containing $q$ would be of little benefit to forecasters unless the effect of $q$ on orders and investment involves very long lags.

This defect could conceivably be remedied if $q$, while exogenous, could at least be linked to policy instruments whose levels must already be assumed for any forecast. Brainard and Tobin have pointed in this direction, arguing that "the valuation of investment goods relative to their cost is the prime indicator and proper target of monetary policy, [because] nothing else, whether it is the quantity of 'money' or some financial interest rate, can be more than an imperfect and derivative indicator of the effective thrust of monetary events and policies." ${ }^{41}$ But in that case a workable link between monetary-policy instruments and $q$ would have to be established before $q$ could serve as a target. As Tobin himself has emphasized, forging such a link will not be easy since not only monetary policy, but also other exogenous events can cause $q$ to change. ${ }^{42}$ I hypothesize that the explicit and implicit (inflation-related) tax-change variables that were previously found to have a powerful effect on the after-tax rate of return on capital employed by nonfinancial corporations may represent such events though not all of them are exogenous. Furthermore, even though I remain convinced that the quarterly capacity-utilization rate should affect the expected profitability of only the most short-lived investments, the nation's shareholders and bondholders may not necessarily act as if they shared that viewpoint. The simple-minded regression results reported above already suggested that capacity utilization and $q$ interact.

39. Ibid., p. 285.

40. For a related critique see Herschel I. Grossman, "Tobin on Macroeconomics: A Review Article," Journal of Political Economy, vol. 83 (August 1975), pp. 837-38. For a brief discussion of the history of $q$ see also Donald D. Hester, "Contributions and Growth in Tobin's Economic Essays: A Review Essay," Journal of Economic Literature, vol. 15 (June 1977), pp. 489-91.

41. Brainard and Tobin, "Pitfalls in Financial Model Building," p. 104.

42. See Tobin, "General Equilibrium Approach to Monetary Theory," p. 29. 


\section{RESULTS}

Regressing $q$ on the same variables used in the $A T R$ equations allows a test of whether the determinants of the after-tax rate of return on capital also influence the market value of nonfinancial corporations relative to the replacement cost of their assets. However, since the influence on $q$ of temporary changes in the tax rate $(R C T)$ and the corresponding permanent changes $(R C P)$, and of permanent changes in the investment tax credit $(I C P)$ and in depreciation allowances $(D C P)$ may differ, the components of explicit tax changes must be run separately. All tax-related variables with the exception of the debt-asset ratio $(D / A)$ are here divided by the replacement cost of "total net assets" shown in column 3 of table 1, and expressed in percent. The dummy variable for the brief suspension of the investment-tax credit starting in October 1966, IC66, which was already explained, is also included in the regressions reported in table 3. Time trends proved to be completely insignificant, suggesting that $q$ has not been dropping for reasons that can be explained only through the makeshift of "time."

It turns out that several of the permanent explicit tax-change variables, and some of the inflation-related implicit ones, are significant in the AOLS equations reported in table 3 . The variables $R C T$ and $D C P$ (not shown) never come close to being significant, indicating that temporary rate changes and permanent depreciation changes, which will later be found to have no significant effect on orders and investment, do not influence $q$ either. $R C P$, on the other hand, has a strong effect on $q$ such that a $\$ 2$ billion permanent cut in annual corporation income taxes, which would lower $R C P$ by 0.1 in 1976, would raise $q$ by 0.03 , or by 4 percent of its sample mean of 0.82 during the first quarter for which the cut is in effect. A tax reduction via the investment tax credit has less impact and is not always statistically significant. An integral specification of the expected effect of permanent tax changes on $q$ yielded similar results. ${ }^{43}$

43. Since permanent tax changes produce a positive or negative rent until the capital stock has been reequilibrated, these rent components, equal to the cumulative amount of the expected change in tax liabilities with the phaseout factors explained in the attached appendix, were summed to the present ignoring discounting. If these rents are instantly capitalized, $q$ should move in line with this integral which declines more steeply with the passage of time after a change in taxes than the phased-out tax change variables in the integrand used in table 3 . However, empirically there was little to choose from since the results on $R C P$ and $I C P$ were no more reliable with the integral than with the integrand specification adopted. 
Table 3. Alternative Estimates of the Determinants of $q$ for Nonfinancial Corporations, Quarterly, 1952:1-1976:4a

\begin{tabular}{|c|c|c|c|c|}
\hline \multirow{2}{*}{$\begin{array}{l}\text { Independent variable and } \\
\text { regression statistic }\end{array}$} & \multicolumn{4}{|c|}{ Equation } \\
\hline & 3.1 & 3.2 & 3.3 & 3.4 \\
\hline \multicolumn{5}{|l|}{ Independent variable } \\
\hline Constant & $\begin{array}{r}0.813 \\
(6.49)\end{array}$ & $\begin{array}{r}1.051 \\
(26.10)\end{array}$ & $\begin{array}{r}0.741 \\
(6.02)\end{array}$ & $\begin{array}{r}0.847 \\
(11.69)\end{array}$ \\
\hline$C U$ & $\begin{array}{c}0.558 \\
(2.71)\end{array}$ & $\begin{array}{c}0.557 \\
(2.77)\end{array}$ & $\begin{array}{c}0.538 \\
(2.55)\end{array}$ & $\begin{array}{c}0.321 \\
(1.61)\end{array}$ \\
\hline IC66 & $\begin{array}{r}0.041 \\
(1.68)\end{array}$ & $\begin{array}{l}0.043 \\
(1.71)\end{array}$ & $\begin{array}{l}0.039 \\
(1.63)\end{array}$ & ... \\
\hline$I C C A$ & $\begin{array}{c}0.188 \\
(4.49)\end{array}$ & $\begin{array}{c}0.197 \\
(5.02)\end{array}$ & $\begin{array}{c}0.178 \\
(4.14)\end{array}$ & $\cdots$ \\
\hline$I V A$ & $\begin{array}{l}0.039 \\
(2.28)\end{array}$ & $\begin{array}{c}0.031 \\
(1.95)\end{array}$ & $\begin{array}{l}0.040 \\
(2.36)\end{array}$ & ... \\
\hline$R C P$ & $\begin{array}{l}-0.290 \\
(-2.91)\end{array}$ & $\begin{array}{l}-0.394 \\
(-4.93)\end{array}$ & $\begin{array}{l}-0.256 \\
(-2.33)\end{array}$ & $\cdots$ \\
\hline$I C P$ & $\begin{array}{l}-0.136 \\
(-0.86)\end{array}$ & $\begin{array}{l}-0.277 \\
(-2.02)\end{array}$ & $\cdots$ & $\cdots$ \\
\hline$D / A$ & $\begin{array}{l}1.058 \\
(1.99)\end{array}$ & $\cdots$ & $\begin{array}{l}1.356 \\
(2.58)\end{array}$ & $\cdots$ \\
\hline \multicolumn{5}{|l|}{ Regression statistic } \\
\hline $\bar{R}^{2}$ & 0.92 & 0.92 & 0.92 & 0.91 \\
\hline Standard error & 0.04 & 0.04 & 0.04 & 0.04 \\
\hline Durbin-Watson & 1.86 & 1.81 & 1.89 & 1.76 \\
\hline$\rho$ & 0.69 & 0.63 & 0.73 & 0.94 \\
\hline $\bar{R}_{u}^{2}$ & 0.85 & 0.86 & 0.83 & 0.03 \\
\hline Standard error & 0.06 & 0.06 & 0.06 & 0.15 \\
\hline Durbin-Watson & 0.61 & 0.72 & 0.54 & 0.09 \\
\hline
\end{tabular}

Sources: $C U$, which is entered minus its mean of 0.833, is from the Board of Governors of the Federal Reserve System; IVA is from U.S. Bureau of Economic Analysis, National Income and Product Accounts of the United States, 1929-74: Statistical Tables (GPO, 1977), table 1.15, and Survey of Current Business, various issues; $D / A$ is column 5 of table 1 divided by column 3 of table $1 ; I C 66$, a dummy variable, is constructed as described in text note $23 ; I C C A$ was derived by the author as described in text note 16; $R C P$ and $I C P$ were estimated by the author and are available from him in a longer version of the appendix; and $q$ is from table 1 , column 9 , divided by $(1-k)$. The variables are as defined in the text. ICCA, IVA, $R C P$, and $I C P$ are divided by total net assets from table 1 , column 3 , and expressed in percentage terms.

a. The method of estimation used in all regressions is ordinary least squares with a correction for firstorder autocorrelation. The numbers in parentheses are $t$ statistics.

The inflation-tax variables, $I V A, I C C A$, and $D / A$, are also generally statistically significant and so are $C U$ and, by a more lenient standard of statistical significance, IC66. In particular, a $-\$ 14$ billion "rise" in the inflation-induced part of the $C C A$, similar to the one that occurred from 1974 to 1976 , which would "raise" the negative ICCA by -0.7 , is esti- 
mated to reduce $q$ by 15 percent of its mean. This makes implicit tax increases a much more poweriful influence on $q$ than explicit tax cuts during this period, although not all of the negative effect of inflation need have been due to fiscal factors. ${ }^{44}$ Simultaneous cyclical factors also have a strong effect in that a 10 percent rise in $C U$ from its mean of 0.833 increases $q$ by 5 to 6 percent. Lagging $C U$ diluted this effect. Furthermore, autocorrelation of the error terms is not overwhelming, and the GreenWatson formula (equation 6) is very nearly satisfied in the first three equations, indicating consistent estimation. The $\bar{R}_{u}^{2}$ is only a few percent below the $\bar{R}^{2}$ of around 0.92 found in those AOLS equations. The fit is better than average in the last year of the estimation period and $q$ is slightly above its predicted value, indicating that the stock and bond markets were not inexplicably low in 1976.

Assuming that monetary and fiscal policy operated in splendid isolation from each other and that none of the explanatory variables picked up the effects of omitted variables, it could be argued that little is left if $q$ is to reflect monetary policy effects, rather than fiscal effects and current cyclical conditions. Such effects would then have to be hidden in the remaining 10 or 15 percent of its total variance (depending on whether the first-order serial-correlation process can somehow be attributed to the conduct of monetary policy ${ }^{45}$ ) along with the random-error term accounting for "the numerous sharp fluctuations in stock prices that appear retrospectively to be unwarranted." 46 Thus, it is not entirely obvious at this stage that $q$ can bring a significant amount of new information to bear on

44. A rise in the rate of inflation that raises the absolute value of $I C C A$ this period will continue to do so over an entire replacement cycle even if the added inflation lasts only one year. Assuming that the discounted cumulative effects are ten times as large as the first-year rise in taxes due to increased underdepreciation and that the effective tax rate is 40 percent, additional taxes of $\$ 56$ billion, or 3 percent of "total net assets" in the denominator of $q$ and ICCA, are generated in the case discussed. If inflation is expected to continue at the higher rate beyond one year, the expected effect on $q$ would be several times larger.

45. Describing the wealth effects of the stock market on consumption, Franco Modigliani has suggested that incorporating such effects leads to a speed-up of the measured response of money GNP to changes in the supply of money. If this speedup applied analogously to investment, the size of the autocorrelation coefficient could decline with the introduction of $q$ into equations for orders and investment. However, the opposite was found. See Franco Modigliani, "Discussion," American Economic Review, vol. 62 (May 1972), p. 230.

46. Irwin Friend, "The Economic Consequences of the Stock Market," American Economic Review, vol. 62 (May 1972), p. 218. 
capital-goods orders and investment. However, should it do so, $q$ would be quite useful in forecasting investment rates since $q$ itself can be forecast along with other variables, even after the effect of the lagged error term $\left(u_{t-1}\right)$ has died down.

\section{Results for Capital-Goods Orders and Investment}

This analysis of the interdependence of $q$ and other explanatory variables sets the stage for specifying three complete equations for orders and investment rates. The first regression for each contains all variables other than $R C T, D C P$, and $D / A,{ }^{47}$ and it omits $q$. The variable $q$, unadjusted except for the division by $(1-k)$ explained above, is added in the second equations. Using the regression coefficients reported in equation 3.2 of table $3, q$ is then adjusted and substituted for the unadjusted $q$ in the third equation reported in each section of table 4 . This should help determine whether $q$ brings additional information to bear on the capital-goods orders and investment process after it has been stripped of the influence of all the other explanatory variables that have a statistically significant effect on it. The regression results are reported in table 4.

Apart from the Almon lags and other differences in the construction of transformed inputs, the linear regression coefficients found in this exercise would be as follows: (1) The coefficients and significance levels of all variables (except for the intercept) reported for equation 4.1 (4.4) in table 4 would be the same as those for equation 4.3 (4.6). (2) The regression coefficient and significance level of $q$ would be the same in equations 4.2 (4.5) and 4.3 (4.6) but the coefficients of all other variables used to adjust $q$ would change both in size and significance. (3) The AOLS coefficient of determination, $\bar{R}^{2}$, and all other summary statistics would be identical in equations $4.2(4.5)$ and $4.3(4.6)$.

47. None of these variables seemed to matter much in either the investment or the orders equation. $R C T$ and $D / A$ were lagged once in the latter while $D C P$ was lagged like the other permanent tax-change variables, $R C P$ and $I C P$. Specifically, the coefficient on $R C T$ was minute and statistically insignificant, the coefficient on $D C P$ was generally negative as expected but never significant, and the coefficient on $D / A$ was positive and close to significant only at the expense of the capital-stockmix variable which also contains a persistent uptrend. Of the two, GE/GPE seemed stronger both statistically and conceptually. 
Table 4. Final Regression Results for the Real Values of the Rate of Contracts and Orders and the Rate of Investment of Nonfinancial Corporations, Alternative Specifications, Quarterly, 1952:1-1976:4

\begin{tabular}{|c|c|c|c|c|c|c|}
\hline \multirow[b]{2}{*}{$\begin{array}{c}\text { Independent variable } \\
\text { and regression } \\
\text { statistic }\end{array}$} & \multicolumn{3}{|c|}{ Rate of contracts and orders } & \multicolumn{3}{|c|}{ Rate of investment } \\
\hline & $\begin{array}{l}\text { Without } q \\
4.1\end{array}$ & $\begin{array}{l}\text { With } q \\
4.2\end{array}$ & $\begin{array}{l}\text { With } \\
\text { adjusted } q^{\mathrm{b}} \\
\quad 4.3\end{array}$ & $\begin{array}{c}\text { Without } q \\
4.4\end{array}$ & $\begin{array}{l}\text { With } q \\
4.5\end{array}$ & $\begin{array}{l}\text { With } \\
\text { adjusted } q^{\mathrm{b}} \\
4.6\end{array}$ \\
\hline \multicolumn{7}{|l|}{ Independent variable } \\
\hline Constant & $\begin{array}{r}11.697 \\
(23.87)\end{array}$ & $\begin{array}{c}4.236 \\
(1.63)\end{array}$ & $\begin{array}{c}7.888 \\
(2.75)\end{array}$ & $\begin{array}{r}7.991 \\
(20.70)\end{array}$ & $\begin{array}{r}3.097 \\
(1.75)\end{array}$ & $\begin{array}{c}2.818 \\
(1.33)\end{array}$ \\
\hline$C U^{0}$ & $\begin{array}{l}19.984 \\
(6.94)\end{array}$ & $\begin{array}{l}15.071 \\
(4.73)\end{array}$ & $\begin{array}{l}18.729 \\
(6.26)\end{array}$ & $\begin{array}{r}9.783 \\
(4.88)\end{array}$ & $\begin{array}{r}5.991 \\
(2.58)\end{array}$ & $\begin{array}{l}7.486 \\
(3.51)\end{array}$ \\
\hline$G E / G P E$ & $\begin{array}{l}29.588 \\
(5.23)\end{array}$ & $\begin{array}{l}27.649 \\
(4.54)\end{array}$ & $\begin{array}{l}27.829 \\
(4.66)\end{array}$ & $\begin{array}{l}16.732 \\
(3.41)\end{array}$ & $\begin{array}{l}16.814 \\
(3.30)\end{array}$ & $\begin{array}{l}15.654 \\
(2.97)\end{array}$ \\
\hline $1 C 66^{\circ}$ & $\begin{array}{c}0.429 \\
(1.30)\end{array}$ & $\begin{array}{c}0.312 \\
(0.99)\end{array}$ & $\begin{array}{c}0.365 \\
(1.11)\end{array}$ & $\begin{array}{c}0.522 \\
(1.72)\end{array}$ & $\begin{array}{r}0.447 \\
(1.54)\end{array}$ & $\begin{array}{c}0.460 \\
(1.57)\end{array}$ \\
\hline$I C C A^{\mathrm{d}}$ & $\begin{array}{c}0.785 \\
(1.76)\end{array}$ & $\begin{array}{l}-0.527 \\
(-0.82)\end{array}$ & $\begin{array}{r}0.793 \\
(1.72)\end{array}$ & $\begin{array}{l}0.556 \\
(1.72)\end{array}$ & $\begin{array}{l}-0.168 \\
(-0.40)\end{array}$ & $\begin{array}{r}0.669 \\
(1.99)\end{array}$ \\
\hline$I V A^{\circ}$ & $\begin{array}{l}-0.429 \\
(-2.16)\end{array}$ & $\begin{array}{l}-0.406 \\
(-2.06)\end{array}$ & $\begin{array}{l}-0.417 \\
(-2.08)\end{array}$ & $\begin{array}{c}0.352 \\
(2.62)\end{array}$ & $\begin{array}{c}0.319 \\
(2.43)\end{array}$ & $\begin{array}{r}0.330 \\
(2.48)\end{array}$ \\
\hline$R C P^{\mathrm{e}}$ & $\begin{array}{r}0.459 \\
(0.40)\end{array}$ & $\begin{array}{l}3.785 \\
(2.13)\end{array}$ & $\begin{array}{r}0.516 \\
(0.42)\end{array}$ & $\begin{array}{l}-2.236 \\
(-1.85)\end{array}$ & $\begin{array}{c}-0.611 \\
(-0.45)\end{array}$ & $\begin{array}{l}-2.811 \\
(-2.23)\end{array}$ \\
\hline$I C P^{\bullet}$ & $\begin{array}{r}1.909 \\
(1.15)\end{array}$ & $\begin{array}{r}2.761 \\
(1.52)\end{array}$ & $\begin{array}{l}1.655 \\
(0.96)\end{array}$ & $\begin{array}{c}0.007 \\
(0.01)\end{array}$ & $\begin{array}{r}0.507 \\
(0.41)\end{array}$ & $\begin{array}{l}-0.513 \\
(-0.41)\end{array}$ \\
\hline$q^{\bullet}$ & $\cdots$ & $\begin{array}{l}7.104 \\
(2.92)\end{array}$ & $\begin{array}{l}3.551 \\
(1.35)\end{array}$ & $\cdots$ & $\begin{array}{r}4.726 \\
(2.83)\end{array}$ & $\begin{array}{r}4.825 \\
(2.50)\end{array}$ \\
\hline \multicolumn{7}{|l|}{ Regression statistic } \\
\hline Standard error & 0.53 & 0.51 & 0.53 & 0.18 & 0.17 & 0.17 \\
\hline Durbin-Watson & 1.96 & 2.09 & 2.01 & 1.50 & 1.65 & 1.63 \\
\hline$\rho$ & 0.54 & 0.61 & 0.57 & 0.85 & 0.88 & 0.88 \\
\hline $\bar{R}_{u}^{2}$ & 0.85 & 0.84 & 0.84 & 0.76 & 0.67 & 0.64 \\
\hline Standard error & 0.64 & 0.65 & 0.65 & 0.41 & 0.49 & 0.50 \\
\hline Durbin-Watson & 0.90 & 0.77 & 0.85 & 0.21 & 0.14 & 0.13 \\
\hline
\end{tabular}

Sources: Same as table 2 or 3 above. ICCA, IVA, RCP, and ICP are here divided by the gross stock of plant and equipment of nonfinancial corporations and expressed in percentage terms. $C U$ and $G E / G P E$ are entered minus their respective means of 0.833 and 0.4672 .

a. The dependent variables are expressed as a percent of the real gross capital stock of plant and equipment of nonfinancial corporations. The method of estimation used in all regressions is ordinary least squares with a correction for first-order autocorrelation. The numbers in parentheses are $t$ statistics.

b. Adjusted $q$ is defined as $q-0.56 C U-0.04 I C 66-0.20 I C C A-0.03 I V A+0.39 R C P+0.28 I C P$. See table 3 above, equation 3.2.

c. The sum of the lag coefficients is reported in the investment equations for $C U, I C 66$, and $I V A$. See table 2 above, note $c$, for a description of the lag structure.

d. In the investment equations $I C C A$ was constructed as a weighted average of its four most recent values, using as weights the fixed coefficients $b_{0}, b_{2}, b_{4}$, and $b_{6}$, reported in the text.

e. In all equations, the sum of the lag coefficients is reported for $q, R C P$, and ICP. See table 2 above, note $d$, for a description of the lag structure. 
Since the lag structure adopted in the investment equation is derived from that obtained in the orders equation using the lag from orders to shipments analyzed above, the rationales for the latter must be explained. As already reported, $C U$ worked best without lags in that equation. Since $C U$ is a decision variable which is planned and adjusted by nonfinancial corporations along with orders in the light of their inventory position and sales expectations, there is no cogent reason for assuming that corporations hark back to earlier $C U$ s in placing orders. Efforts to introduce variables reflecting disappointed sales expectations and relative-price changes directly into the orders and investment equations proved unsuccessful. Rather, both capacity utilization and orders may well be determined simultaneously, so that whatever affects the utilization rate also affects orders with about the same lag.

However, it takes more time to react to changes in $q$, which are often due to factors external to individual corporations; and it also takes longer to respond to explicit permanent tax changes, which generally are designed to avoid economic disruptions. Hence these variables were entered with lags constrained to zero for lead periods and for lags in excess of three quarters in the orders equation on the theory that four quarters should provide adequate time to react.

The choice of lag on the inventory valuation adjustment depends to some extent on what one is trying to explain. The variable $I V A$ is scaled by the nominal value of the gross stock of plant and equipment of nonfinancial corporations, as are other tax-related variables because all are in nominal dollars. If an increase in prices and in the absolute value of this IVA coincides with a scramble to beat price increases before they reach the finished-goods stage, IVA should be entered without lags in the orders equation. On the other hand, longer lags would be in order if $I V A$ is to reflect the influence of tax factors and of the profit squeeze that appears to result from inflation (as the results on the after-tax rate of return reported in the appendix suggest). The expected sign of the coefficient on IVA (itself signed as in the national income accounts) would then change from negative to positive. After some experimentation I decided to use no lag on $I V A$ in the orders equations.

The same choice was made for IC66, GE/GPE, and ICCA, although the last clearly reflects the cumulative and not just the short-term effects of inflation on $A T R$. However, because the negative ICCA moves gradually over the 1952:1-1976:4 estimation period, first declining and then 
rising, ${ }^{48}$ there would be no point in estimating a distributed lag for this variable. This applies also to the investment equations in which $I C C A$ was constructed as a weighted average of its four most recent past values, using the fixed coefficients, $b_{0}, b_{2}, b_{4}$, and $b_{6}$, reported above, as weights. ${ }^{49}$ The variable $G E / G P E$ moves up throughout the data period, but at a snail's pace, so that variable needs no distributed lags either. ${ }^{50}$

Second-degree Almon lag polynominals were, however, used for all the other variables in the investment equations after lags had been lengthened just as the orders-to-shipments relation prescribed. All variables used in the orders equation were first lagged one additional quarter to preclude any simultaneous effect of new orders on shipments, and the maximum length of lags was then extended by three quarters, for a total of four quarters.

Comparing the results for orders and investment rates in table 4 shows that the sign patterns are consistent for $q$ and for the first four variables, $C U, G E / G P E, I C 66$, and ICCA. The mean of the annualized contracts and orders rate of 11.0 percent exceeds the 7.5 percent mean for the investment rate because all capital-goods orders, and not just those placed by nonfinancial corporations, are included in the numerator of the orders rate. For this reason, the absolute values of the regression coefficients are generally greater in the orders equation, but their significance is comparable to those found in the corresponding investment equations.

Sign conflicts arise in connection with the variables $R C P$ and ICP. Insignificant "wrong" or positively signed coefficients on these variables are damaging in the orders equations even though total contracts and orders for plant and equipment may be less affected by permanent tax changes in the corporate sector than corporate contracts and orders alone. Corporate-tax changes may cause some investment activity to shift between the corporate and the noncorporate sectors in which nonresidential capital is employed. The sign conflict in IVA is more troublesome. The

48. $I C C A$ "declined" from -1.2 percent of the gross stock of plant and equipment of nonfinancial corporations in the mid-fifties to about -0.6 percent in 1964-65 as the effects of wartime inflation waned. It then "climbed" to -2.0 percent in 1976 , reflecting a new wave of inflation.

49. An attempt to estimate flexible coefficients of the form $\left(b_{i}+b_{j} U / S\right)$ on $C U$ for the subsample 1958-76 failed so that the fixed basic coefficients were used to construct this weighted average.

50. $G E / G P E$ was used without lags even in the investment equations since its rise was so slow that a gain of 0.01 occurred only about once every two years. 
orders equations all suggest that a surge in inflation that raises the absolute value of the IVA stimulates capital-goods orders simultaneously, but the investment equations indicate that investment by nonfinancial corporations is depressed wih a lag. These seemingly contradictory findings can be reconciled if the "beat inflation" psychology driving up orders in one quarter leads to some lengthening of the average lag from new orders to shipments. ${ }^{51}$

With these possible exceptions, the results for orders and for investment are broadly consistent. While about 90 percent of the variance in the order rates is "explained" by the AOLS regressions, compared with 95 percent of the variance of investment rates, autocorrelation of the error terms is much smaller in the former. Thus, $\bar{R}_{u}^{2}$ is higher for orders than for investment rates and the Green-Watson formula is almost precisely satisfied in the orders equations, indicating consistent estimation.

The strength of several of the coefficients on which a statistical consensus could be reached is worth exploring. In the investment equations, raising $C U$ by 0.025 , or 3 percent of its mean of 0.833 , would have boosted the investment rate by between 2 and 3 percent of its mean after one year. The 0.12 updrift in the capital-mix variable over the estimation period raised the gross investment rate by almost 2 percentage points from 1952 to 1976 , or by considerably more than the rise of 0.76 percentage point in the discard rate estimated for this period with BEA data. Even though the coefficient of $G E / G P E$ may thus well have been boosted by some of the positive effects of other time-linked variables-such as $D / A$, which will later be shown to be significant in the equation for equipment investment alone - this finding is reliable enough to suggest that the replacement rate cannot be treated as approximately constant in time-

51. Some empirical support was found for this interpretation. The ratio of unfilled orders to shipments $(U / S)$ at the end of a quarter in the industry "machinery, except electrical," which furnishes most equipment investments, showed a strong positive link to annualized percentage changes in the deflator for the gross domestic product of nonfinancial corporations (NFCPGNP) from that to the succeeding quarter even after allowing for an independent rise over time by use of the trend variable $T$. The quarterly regression estimate for the period 1958-76 is

$$
\begin{gathered}
U / S=2.304+0.088 \Delta N F C P G N P+0.039 T . \\
(25.32)(5.06) \quad(13.63) \\
R^{2}=0.89 ; \text { standard error }=0.38 . \\
\text { The numbers in parentheses are } t \text { statistics. }
\end{gathered}
$$

This indicates that a rise in the rate of inflation does, in fact, stimulate orders temporarily with delivery taken later than usual to beat price increases on new orders. 
series analyses of plant and equipment investment combined. Less reliably, according to equations 4.4 and 4.6, a "rise" of -0.6 in $I C C A$, which would be produced by an absolute increase of $\$ 10$ billion in the inflationinduced part of the $C C A$ for nonfinancial corporations given that their gross stock of nonresidential capital was about $\$ 1.7$ trillion in 1976, would depress the investment rate by 5 percent. The effect of explicit tax changes is less clear. ${ }^{52}$ Finally, a maintained 3 percent rise in $q$, whose mean is almost identical to that of $C U$, would have raised the investment rate by 2 percent or less after two years if the regression results are to be believed. Since the standard deviation of the adjusted $q(0.05)$ is as small as that of $C U$, the relative importance of these variables is proportional to the size of their regression coefficients.

Overall, the addition of the unadjusted $q$ in equations 4.2 and 4.5 yields little or no improvement in fit and greatly increases serial correlation of the error terms. The coefficient on one variable, ICCA, which is strongly correlated with $q$, now becomes negative while its expected sign is unequivocally positive. Adjusting $q$ by eliminating the influence of all the other explanatory variables on $q$ overcomes this problem in equations 4.3 and 4.6. Yet serial correlation remains higher and $\bar{R}_{u}^{2}$ is always lower than in the equations without $q$. However, in none of the investment equations did the estimated absolute error, $\hat{\epsilon}$, exceed 0.18 , which is about equal to the standard error of estimate during the period 1974:2 through 1976:4. Hence, investment behavior was not demonstrably unusual during the past few years in relation to the explanatory variables.

All of these results are confirmed in table 5 when real investment in equipment and the series, "value of manufacturers' new orders, capital goods industries, nondefense, in 1972 dollars" are used to construct new dependent variables referring to equipment alone. Equipment orders and investment are expressed in percent of the gross stock of equipment in

52. Assuming, partly for the sake of illustration, that the sum of the lag coefficients on $R C P$ is -2 in the investment equation, what would a permanent corporaterate cut costing $\$ 5$ billion annually accomplish? With 1976 magnitudes, such a cut would reduce $R C P$ by about 0.3 . The cumulative effect on the gross investment rate reached after seven years is 1.5 percent of the real gross stock of capital employed by nonfinancial corporations. Since in 1976 this stock amounted to $\$ 1.2$ trillion in 1972 dollars, a cumulative increase in real gross investment of about $\$ 18$ billion is involved during the adjustment period. When the gross investment rate has fallen back to its original level after seven years, annual gross investment remains 1.5 percent higher than in the absence of the permanent rate cut. 
Table 5. Regression Results for the Real Values of the Rate of New Orders of Nondefense Capital-Goods Industries and the Rate of Investment in Equipment, Nonfinancial Corporations, Alternative Specifications, Quarterly, 1952:1-1976:4

\begin{tabular}{|c|c|c|c|c|c|c|}
\hline \multirow[b]{2}{*}{$\begin{array}{c}\text { Independent variable } \\
\text { and regression } \\
\text { statistic }\end{array}$} & \multicolumn{3}{|c|}{ Rate of new orders } & \multicolumn{3}{|c|}{ Rate of investment } \\
\hline & $\begin{array}{l}\text { Without } q \\
\quad 5.1\end{array}$ & $\begin{array}{l}\text { With } q \\
5.2\end{array}$ & $\begin{array}{c}\text { With } \\
\text { adjusted } q^{\mathrm{b}} \\
5.3\end{array}$ & $\begin{array}{c}\text { Without } q \\
5.4\end{array}$ & $\underset{5.5}{\text { With } q}$ & $\begin{array}{l}\text { With } \\
\text { adjusted } q^{\mathrm{b}} \\
5.6\end{array}$ \\
\hline \multicolumn{7}{|l|}{ Independent variable } \\
\hline Constant & $\begin{array}{c}15.872 \\
(5.16)\end{array}$ & $\begin{array}{c}3.162 \\
(0.55)\end{array}$ & $\begin{array}{l}13.467 \\
(2.39)\end{array}$ & $\begin{array}{c}4.896 \\
(2.05)\end{array}$ & $\begin{array}{c}-3.923 \\
(-0.95)\end{array}$ & $\begin{array}{l}-2.387 \\
(-0.52)\end{array}$ \\
\hline$C U^{\mathfrak{c}}$ & $\begin{array}{l}31.644 \\
(5.81)\end{array}$ & $\begin{array}{l}21.722 \\
(3.54)\end{array}$ & $\begin{array}{l}31.358 \\
(5.69)\end{array}$ & $\begin{array}{l}11.359 \\
(3.20)\end{array}$ & $\begin{array}{c}4.575 \\
(1.11)\end{array}$ & $\begin{array}{c}9.671 \\
(2.70)\end{array}$ \\
\hline$D / A^{\mathrm{d}}$ & $\begin{array}{l}16.559 \\
(1.27)\end{array}$ & $\begin{array}{l}13.591 \\
(0.96)\end{array}$ & $\begin{array}{l}18.432 \\
(1.36)\end{array}$ & $\begin{array}{l}23.157 \\
(2.33)\end{array}$ & $\begin{array}{c}24.696 \\
(2.35)\end{array}$ & $\begin{array}{l}31.537 \\
(2.80)\end{array}$ \\
\hline $1 C 66^{\circ}$ & $\begin{array}{c}0.690 \\
(1.17)\end{array}$ & $\begin{array}{c}0.478 \\
(0.85)\end{array}$ & $\begin{array}{r}0.649 \\
(1.09)\end{array}$ & $\begin{array}{r}0.399 \\
(0.74)\end{array}$ & $\begin{array}{c}0.255 \\
(0.50)\end{array}$ & $\begin{array}{c}0.360 \\
(0.68)\end{array}$ \\
\hline$I C C A^{\circ}$ & $\begin{array}{c}0.246 \\
(0.55)\end{array}$ & $\begin{array}{l}-0.862 \\
(-1.36)\end{array}$ & $\begin{array}{c}0.453 \\
(0.75)\end{array}$ & $\begin{array}{r}0.177 \\
(0.62)\end{array}$ & $\begin{array}{c}-0.462 \\
-(1.23)\end{array}$ & $\begin{array}{c}0.746 \\
(1.84)\end{array}$ \\
\hline$I V A^{\mathrm{c}}$ & $\begin{array}{l}-0.456 \\
(-2.36)\end{array}$ & $\begin{array}{l}-0.444 \\
(-2.33)\end{array}$ & $\begin{array}{c}-0.434 \\
(-2.18)\end{array}$ & $\begin{array}{r}0.189 \\
(1.50)\end{array}$ & $\begin{array}{c}0.165 \\
(1.35)\end{array}$ & $\begin{array}{r}0.257 \\
(1.98)\end{array}$ \\
\hline$R C P^{\mathrm{f}}$ & $\begin{array}{l}-0.704 \\
(-0.55)\end{array}$ & $\begin{array}{r}1.636 \\
(0.88)\end{array}$ & $\begin{array}{c}-0.983 \\
(-0.71)\end{array}$ & $\begin{array}{l}-1.037 \\
(-0.95)\end{array}$ & $\begin{array}{r}0.387 \\
(0.31)\end{array}$ & $\begin{array}{l}-1.899 \\
(-1.61)\end{array}$ \\
\hline$I C P^{\mathrm{f}}$ & $\begin{array}{r}1.804 \\
(0.94)\end{array}$ & $\begin{array}{c}1.992 \\
(0.96)\end{array}$ & $\begin{array}{c}1.788 \\
(0.94)\end{array}$ & $\begin{array}{c}0.182 \\
(0.15)\end{array}$ & $\begin{array}{r}0.589 \\
(0.48)\end{array}$ & $\begin{array}{c}0.182 \\
(0.15)\end{array}$ \\
\hline$q^{\mathrm{f}}$ & $\cdots$ & $\begin{array}{l}12.770 \\
(2.69)\end{array}$ & $\begin{array}{l}2.315 \\
(0.51)\end{array}$ & $\ldots$ & $\begin{array}{r}8.169 \\
(2.77)\end{array}$ & $\begin{array}{c}6.274 \\
(1.92)\end{array}$ \\
\hline \multicolumn{7}{|l|}{ Regression statistic } \\
\hline $\bar{R}^{2}$ & 0.86 & 0.87 & 0.86 & 0.93 & 0.93 & 0.93 \\
\hline Standard error & 0.97 & 0.94 & 0.98 & 0.32 & 0.31 & 0.32 \\
\hline Durbin-Watson & 1.93 & 2.02 & 1.94 & 1.68 & 1.82 & 1.78 \\
\hline$\rho$ & 0.62 & 0.69 & 0.61 & 0.84 & 0.86 & 0.85 \\
\hline $\bar{R}_{u}^{2}$ & 0.77 & 0.75 & 0.77 & 0.66 & 0.55 & 0.60 \\
\hline Standard error & 1.26 & 1.32 & 1.26 & 0.69 & 0.80 & 0.74 \\
\hline Durbin-Watson & 0.68 & 0.55 & 0.69 & 0.25 & 0.17 & 0.20 \\
\hline
\end{tabular}

Sources: The new-orders variable is from Business Conditions Digest, various issues, series 27; data for the investment variable were furnished by the U.S. Bureau of Economic Analysis, with quarterly estimates derived according to text note 32. For all other variables, see table 2 or 3 above. ICCA,IVA, $R C P$, and $I C P$ are here divided by the gross stock of equipment of nonfinancial corporations, and expressed in percentage terms. $C U$ is entered minus its mean of 0.833 .

a. The dependent variables are expressed as a percent of the real gross stock of equipment of nonfinancial corporations. The method of estimation used in all regressions is ordinary least squares with a correction for first-order autocorrelation. The numbers in parentheses are $t$ statistics.

b. Adjusted $q$ is defined as $q-0.56 C U-0.04 I C 66-0.19 I C C A-0.04 I V A+0.29 R C P+0.14 I C P$

$-1.06 D / A$. See table 3 above, equation 3.1.

c. The sum of the lag coefficients is reported in the investment equations for $C U, I C 66$, and $I V A$. See table 2 above, note $c$, for a description of the lag structure.

d. See text note 53 for a description of $D / A$ as constructed for the investment equations. In the orders equation, $D / A$ is lagged one quarter.

e. See table 4 above, note $d$, for a description of ICCA as constructed for the investment equations.

f. In all equations, the sum of the lag coefficients is reported for $q, R C P$, and $I C P$. See table 2 above, note $d$, for a description of the lag structure. 
1972 dollars, and tax-related variables are similarly scaled by the nominal gross stock of equipment of nonfinancial corporations. All other variables and the lag structures are unaffected except that the variable reflecting the capital-stock mix, $G E / G P E$, no longer applies and that $D / A$, lagged once in the orders equation, is added to capture the tax benefits from debt financing which grow over time. ${ }^{53}$

Even though one might have expected that the effects of IC66 and $I C P$ would be stronger on equipment investment alone than on total investment, ${ }^{54}$ the influence of both variables as well as that of $R C P$ is still not well defined in table 5, and the significance levels of all regression coefficients are about the same as before. Because the turnover of the stock of equipment is much higher than that of structures, the means of the dependent variables are higher for equipment alone ${ }^{55}$ and this accounts for an increase in the absolute size of some of the coefficients in table 5 compared with the corresponding equations in table 4 . Serial correlation remains high in equations with $q$. Although $q$ continues to be significant at the 5 percent level in equations 5.2 and 5.5, it adds little to the explanatory power of the AOLS regressions and detracts from their usefulness in forecasting outside the observed error band. Furthermore, the adjusted $q$ is no longer statistically significant in equations 5.3 and 5.6.

\section{Concluding Comments}

From this analysis, I conclude that the use of $q$ in equations for capitalgoods orders and investment must be regarded as optional at this stage. Using variables in addition to $q$ is mandatory; otherwise, the resulting estimates are prone to be either inconsistent statistically or fraught with such serious autocorrelation of the error terms as to beg the question of how such a process can be generated or convincingly explained by use of

53. Since $D / A$ rises from 0.17 to 0.26 over the estimation period except for one slight fallback that started in 1967, a weighted average was constructed for this variable with lags from two through five quarters in the investment equation. The four weights were $0.20,0.44,0.28$, and 0.08 , the same as those used for $I C C A$.

54. This is particularly disappointing in view of the findings of Hall and Jorgenson in "Application of the Theory of Optimum Capital Accumulation."

55. The annualized means of the equipment orders and investment rates are 19.2 and 9.7 percent, respectively, and the gross stock of equipment in current and constant dollars was $\$ 897$ billion and $\$ 635$ billion, respectively, in 1976 for nonfinancial corporations. 
$q$. On the other hand, adding $q$ to other explanatory variables does not seem equally obligatory since variations in investment and order rates can be explained quite well without it. Furthermore, the unadjusted $q$, while strongly correlated with some "nonfinancial" variables, does not distill all their effects on orders and investment. The factors influencing $q$, among them $C U$ and the inflation-related $I V A$ and $I C C A$, are also not all the same as those that are allowed to change the rental cost of capital in neoclassical formulations so that the securities-valuation model cannot be regarded as a substitute for a neoclassical specification in empirical work. If $q$ is to remain in contention as a "financial" variable, as it should, it will have to be adjusted and then compete with other variables in aggregate investment and orders equations. ${ }^{56}$ However, like the unadjusted $q$ values, the residual $q$ variables constructed in this paper, which could conceivably convey the effects of not directly observable changes in the real interest rate, expectations, and risk aversion, served mainly to increase serial correlation, though $q$ is statistically significant in five out of eight multiple regressions.

Because the theory explaining why $q$ should matter greatly to investment is most persuasive, this finding is distressing. Perhaps, however, it is not as surprising as it may seem at first, considering the aggregate nature of the changes in $q$ used in this paper.

Stocks do not move up and down precisely in unison; some stocks, indeed, are known to move counter to the averages. Still, since the aggregate $q$ mirrors major and persistent changes in the $q$ of most firms, it may be instructive to ask how firms should react to a uniform decline in the stock market that leaves their relative positions unchanged. After such a development they would be no more likely to merge through an exchange of stock or through stock tenders since the value of the stock of all of them has declined by the same proportion, leaving the equity cost (as opposed to cash cost) of acquisitions unchanged.

Corporations would still have an incentive to use cash tenders financed either by drawing down liquid assets or by issuing debt to acquire investment goods second-hand rather than through new orders from capital-

56. Some of the adjustments may be excessive if monetary and fiscal policy pursue similar goals. For instance, in the fall of 1966, suspension of the investment tax credit, a credit crunch, and a decline in the stock market all came together so that it is difficult to know whether eliminating the effect of IC66 on $q$ does not also take out some relevant financial effects arising during the suspension period. 
goods producers. However, mergers financed in this way are generally small in relation to the size of the acquiring company and hardly sufficient to drive up average stock prices, even if legal obstacles to mergers could be ignored.

With a uniform decline in the stock market, corporations may still choose, instead of investing in producers' durables, to increase their financial investment and liquid assets, or reduce their debt or repurchase stock in hopes of raising their average $q$. Since stockholders need not be convinced that a firm's financial management is necessarily superior to its plant, production, and sales management, such a policy is unlikely to succeed for individual firms, and stockholders may press for increased payout. ${ }^{57}$ If many firms nevertheless reduce their net liabilities outstanding, such a policy will ultimately raise the market valuation of all corporate liabilities relative to other assets in investor portfolios (although this portfolio-composition effect is external to the individual firm).

To the extent expansion is financed internally, nothing evident here compels firms to reduce their investment in producers' durables when their $q$ has declined spontaneously, and not just in sympathy with negative nonfinancial factors already in evidence, by as much as everybody else's. No major relevant alternative is demonstrably superior to proceeding with internally financed investment as usual when $q$, adjusted for cyclical, inflation, and tax effects, declines uniformly. Thus, the forces driving the adjusted $q$ back to equilibrium may be extremely weak. This may explain why the autocorrelation-adjustment coefficient, $\rho$, is still fairly high in the equation for $q$ and why the inclusion of $q$ in the investment and orders equations, in turn, increases the degree of autocorrelation of the error terms in those equations.

As to the external financing, it remains true that the cost of new equity issues is raised by a decline in the value of equity in the numerator of $q$. The cost of debt finance may increase at the same time; in fact $q$ has

57. Increasing dividend payout rates may be resisted because it implies a hardto-reverse commitment to slower growth which individual companies are loath to make unless their competitors do likewise. In 1971, the ratio of dividends to after-tax corporate profits with inventory valuation adjustment and capital consumption adjustment plus the reduction in real indebtedness was 48.7 percent, compared with 48.4 percent in 1976 . Hence there is no evidence that corporations as a group have chosen to increase dividend payout under the pressure of a succession of low $q$ s. For the estimated reduction in real indebtedness see von Furstenberg and Malkiel, "Financial Analysis in an Inflationary Environment," p. 578. 
moved inversely to nominal interest yields, such as the rate on A bonds, during 1965-76. But the cost of debt will not necessarily rise if the growth of the money supply is not reduced when the equity component of $q$ declines.

As the supply of new equity issues dwindles and the volume of bond offerings grow, lenders may well be willing to absorb greater amounts of corporate debt and fewer stocks without a significant rise in the bond rate. I know of no empirical demonstration that the aggregate real bond rate has risen systematically over the last decade on account of the growth in the share of debt in the market value of firms. ${ }^{58}$ Given the difficulties of inferring the relevant after-tax real rates from nominal bond yields, the prospects that a convincing demonstration can ever be made appear slim. ${ }^{59}$ What is true, ceteris paribus, for individual firms with rising debtequity ratios thus need not be true in the aggregate when most firms experience a similar fate and traditional credit standards and lending prescripts have time to adjust to a change in circumstances prevailing everywhere. Also, the $q$ equations yielded no evidence that a rise in the debtfinancing percentage depresses $q$ on account of increased leverage risks, particularly for stockholders. Hence nonfinancial corporations taken together may not yet have exceeded the debt-financing percentage that financial investors regard as "optimal." Thus it is not obvious that the nonfinancial corporate sector must experience a marked increase in the cost of external funds and react with a reduction in externally financed investment to a decline in $q$; this observation holds at least for those companies favored with access to the bond market, who can become more heavily dependent on debt funds as time goes on or until the adjusted $q$ revives.

58. The growth in the share of debt in the market value of nonfinancial firms can be calculated readily from table 1 . From 1968:4 to $1974: 4$ the share grew from 23 percent to 45 percent, but it then declined to 38 percent in 1976:4.

59. Tobin and Brainard compute an illustrative Baa "real" rate by subtracting the geometric average inflation rate of the preceding five years. However, on this basis, the "real" Baa rate was found to rise consistently from 1964 to 1970 and to fall consistently from 1970 to 1973 while the share of debt rose. Hence the odds are against finding a significant positive effect of higher debt ratios on the Baa yield. See Tobin and Brainard, "Asset Markets," pp. 255-56, 261. For diverse comparisons of equally rationally construed expected real rates with the ex post real rate on shortterm instruments, see J. W. Elliott, "Measuring the Expected Real Rate of Interest: An Exploration of Macroeconomic Alternatives," American Economic Review, vol. 67 (June 1977), pp. 429-44. 
One final caution: While balance-sheet factors and market valuations may not have been of major consequence for aggregate investment to date, it is dangerous to extrapolate this tentative finding. Perhaps, corporate investment planners hold inelastic and infrequently revised expectations about the normal or "permanent" level of $q$ or of more readily observable variables with similar information content. However, should the unadjusted $q$ continue below its normal level of around 0.8 for very much longer, their convictions may eventually be shaken. Even though the adjusted $q$ was slightly above its average during the last half of 1976 , and even though the unadjusted $q$ may be telling corporate investment planners little more than what they already know by looking at current inflation, capacity utilization, and tax factors, they may come more and more to share the negative sentiments of investors. They may lose confidence that $q$ will tend, as it has done in the past, to come along in any cyclical recovery that is not accompanied by accelerating inflation.

For the time being, however, the reach of capacity utilization above its 1952-76 average level of 0.833 and the continued containment of inflation in 1977 seem more important in appraising the outlook for investment in 1978 than the likelihood that $q$ reached a new low in 1977. The coming year should thus bring a clear test of how little-or how much$q$ matters when it moves counter to "nonfinancial" variables with which it is normally correlated closely. In the meantime, the search for variables other than the residual $q$ that may properly reflect the influence of "financial" factors on investment under inflationary conditions must continue.

\section{APPENDIX}

\section{Tax Factors and the After-Tax Rate of Return of Nonfinancial Corporations}

THE AFTER-TAX return on the domestic capital employed by nonfinancial corporations consists of profits on the national income accounts basis with the inventory valuation adjustment, $I V A$, and capital consumption adjustment, $C C A$, minus profits-tax liabilities and plus net interest paid. This total is divided by the replacement cost of the net fixed capital stock, inventories, and land ("other assets" in table 1) and the result multiplied 
by 100 to yield quarterly estimates of the annualized after-tax rate of return, $A T R$. While it can be argued that the net noninterest-bearing financial assets of corporations also yield productive services, I decided to follow Feldstein and Summers in omitting such assets from the denominator.

Because of the existence of fixed costs and cyclical factors, which influence the width of the markup applied to unit variable costs, the after-tax rate of return is positively related to the capacity-utilization rate, $C U$, which is entered as one-hundredth of the Federal Reserve index of capacity utilization in manufacturing minus its mean of 0.833 . While I regard capacity utilization as a variable that is much more relevant for the determination of the returns on capital than the unemployment rate or the output gap, changes in the total civilian unemployment rate are used to capture asymmetries during the business cycle. With labor hoarding depressing profits in the downswing and more intensive utilization of labor bolstering profits in the upswing, one would expect the change in the unemployment variable, $D U$, to have a negative influence on the rate of return at a given $C U$.

Even a neutral inflationary process that does not affect price-cost relationships before taxes affects after-tax profits to the extent that it raises inventory profits and lowers the real value of depreciation allowances while higher inflation premiums gradually raise the real value of the deductibility of net interest paid. However, book profits are also influenced by changes in depreciation rules and in tax service lives. Attempting to separate the effects of inflation and of changes in the law, I use the variables $I V A, I C C A$, and $D / A$ described in the text for the former and treat the depreciation provisions as one of the components of the total taxchange variable, $T R$. Since additional acceleration is, in fact, only gradually adopted by business once it is permitted by law, I use BEA estimates of the annualized changes in federal profits-tax receipts that have resulted from changes in depreciation provisions as a guide.

The last variable, $T R$, which represents all major explicit tax changes and is expressed in percent of the same capital-stock variable as $A T R$, $I V A$, and ICCA, is the most difficult to construct. Changes in tax accruals due to permanent statutory changes in federal corporate-profits tax rates, in the investment tax credit, and in depreciation provisions must be determined and then phased out over time. Tax amounts resulting from temporary tax changes must be estimated and entered with a weight of 
1 for as long as they remain in effect. While state and local tax changes are, of course, just as relevant in principle, I assume that such changes and the adjustments they induce are sufficiently small and continuous as to produce no major displacements. The phaseout is handled by applying weights $(w)$, calculated from a quadratic (reverse) Pascal distribution function, starting at 1 in the quarter $(k=-1)$ in which the tax change is made, to the variable tax amounts resulting from or saved by a permanent change in law in that and subsequent quarters. ${ }^{60}$ Analytically,

$$
w_{k}=(1-p)^{k+1}[1+(k+1) p],
$$

where $p$ is a small fraction determining the rate at which the weights decline.

If $p$ is as large as 0.18 , the response of investment to the change in taxes is substantially completed within five years; while, at the upper end of the plausible range, lags extending over a period of up to seven years imply a $p$ of $0.12 .{ }^{61}$ Adding one year to eliminate the tail of each distribution, I therefore experimented with alternative lag structures in constructing the numerators of $T R 24$ and $T R 32$, where the numeral on $T R$ indicates the maximum length of lag in quarters. ${ }^{62}$

60. This distribution function of the weights showing the fraction of the total tax effects still to come in any quarter yields a pattern of first accelerating and then decelerating decline. A parabolic frequency function yielding such a pattern is called for since almost all studies of tax effects on investment have found that the investment impact of any tax change reaches its peak two or three years after any change.

61. For a discussion of lag structures see Dale W. Jorgenson and James A. Stephenson, "The Time Structure of Investment Behavior in United States Manufacturing, 1947-1960," Review of Economics and Statistics, vol. 49 (February 1967), pp. 16-27; and the two articles by Dale W. Jorgenson, Jerald Hunter, and M. Ishaq Nadiri, "A Comparison of Alternative Econometric Models of Quarterly Investment Behavior," Econometrica, vol. 38 (March 1970), pp. 187-212, and "The Predictive Performance of Econometric Models of Quarterly Investment Behavior," ibid., pp. 213-24. See also Charles W. Bischoff, "Business Investment in the 1970s: A Comparison of Models," BPEA, 1:1971, pp. 13-58.

62. To give an indication of the time shape of the weights used, the weights are shown for the third quarter after any change $(k=2)$, the seventh quarter after, and so on every four quarters up to the twenty-third or thirty-first quarter, as applicable. For $T R 24$, these weights are $0.85,0.56,0.34,0.19,0.10$ and 0.02 . For $T R 32$, they are $0.93,0.75,0.57,0.41,0.29,0.20,0.12$, and 0.01 . The tail of the distribution is wedged off linearly during the sixth year for $T R 24$ and over the last six quarters for $T R 32$. A table showing the estimated components of the numerator of TR24 is contained in a longer version of this appendix available from the author. 


\section{Interpretation of Results}

Regression results obtained with both $T R 24$ and $T R 32$ are reported in table A-1, with a time trend $(T)$ contained in some runs. Overall, these two sets of equations yield similar results. A slight preference in favor of the shorter lag structure reflected in the construction of $T R 24$ can be established only by considering the expected size of the coefficient on $T R$. If tax changes are not systematically related to cyclical conditions, so that tax increases do not always come in advanced stages of expansions and tax cuts in severe contractions as automatic implementation of stabilization rules might suggest, $T R$ should have a coefficient not significantly different from -1 . In that case, a $\$ 1$ cut in corporate income taxes would simply produce an equal addition to the after-tax return before the capital stock has had time to adjust. The coefficients on $T R$ meet this requirement at the 5 percent level only with $T R 24$.

Similarly, the coefficients on both ICCA and IVA should not be significantly different from the average tax rate on corporate income of around 0.4 if these variables reduce the after-tax return simply by the amount of the additional taxes due to a rise in underdepreciation or in inventory profits. This requirement is met for $I C C A$, but the coefficient on $I V A$ is significantly greater than 0.4 in all equations; the difference from 0.4 is significant not because the coefficient is much larger than that on ICCA, but because its standard error is much smaller.

Bursts of inflation thus appear to depress the after-tax return not only on account of the additional tax liabilities precipitated by inventory profits but for other reasons as well. ${ }^{63}$

As expected, a rising debt-asset ratio provides some relief from the tax effects of inflation and bolsters the after-tax rate of return. However, this finding is clouded by the trendlike rise in the debt-asset ratio $(D / A)$ from 17 percent in 1952:1 to 26 percent in 1976:4. In fact, table A-1 shows that if time is run together with $D / A$, the time trend retains its sig-

63. The fear that contractive monetary and fiscal policies may be triggered by inflation may delay the adjustment of final-goods prices to cost increases. Contract rigidities and adjustment lags can also prevent increases in prices of basic-materials inputs from passing through quickly to the finished-goods stage so that processing margins may decline, particularly in the administered-price sectors of the economy. For an analysis of the latter issue, see Steven Lustgarten, Industrial Concentration and Inflation (American Enterprise Institute, 1975). 
Table A-1. Regression Results for the After-Tax Rate of Return of Nonfinancial Corporations, Alternative Specifications, Quarterly, 1952:1-1976:4

\begin{tabular}{|c|c|c|c|c|c|c|}
\hline \multirow{2}{*}{$\begin{array}{l}\text { Independent variable } \\
\text { and regression statistic }\end{array}$} & \multicolumn{3}{|c|}{ TR lagged 24 quarters $^{\mathrm{b}}$} & \multicolumn{3}{|c|}{$T R$ lagged 32 quarters $^{\mathrm{b}}$} \\
\hline & A.1 & $A .2$ & $A .3$ & A.4 & $A .5$ & A.6 \\
\hline \multicolumn{7}{|l|}{ Independent variable } \\
\hline Constant & $\begin{array}{l}4.643 \\
(6.66)\end{array}$ & $\begin{array}{r}5.830 \\
(19.26)\end{array}$ & $\begin{array}{r}5.460 \\
(7.28)\end{array}$ & $\begin{array}{r}4.836 \\
(7.93)\end{array}$ & $\begin{array}{r}5.830 \\
(22.00)\end{array}$ & $\begin{array}{r}5.669 \\
(8.05)\end{array}$ \\
\hline$C U$ & $\begin{array}{c}11.604 \\
(11.39)\end{array}$ & $\begin{array}{c}12.033 \\
(12.11)\end{array}$ & $\begin{array}{c}11.983 \\
(11.93)\end{array}$ & $\begin{array}{r}11.799 \\
(12.32)\end{array}$ & $\begin{array}{r}12.153 \\
(12.98)\end{array}$ & $\begin{array}{l}12.122 \\
(12.78)\end{array}$ \\
\hline$D U$ & $\begin{array}{l}-0.222 \\
(-4.29)\end{array}$ & $\begin{array}{l}-0.216 \\
(-4.26)\end{array}$ & $\begin{array}{l}-0.216 \\
(-4.24)\end{array}$ & $\begin{array}{l}-0.231 \\
(-4.69)\end{array}$ & $\begin{array}{l}-0.225 \\
(-4.68)\end{array}$ & $\begin{array}{l}-0.225 \\
(-4.65)\end{array}$ \\
\hline$T R$ & $\begin{array}{l}-1.283 \\
(-7.30)\end{array}$ & $\begin{array}{l}-1.321 \\
(-7.82)\end{array}$ & $\begin{array}{l}-1.311 \\
(-7.68)\end{array}$ & $\begin{array}{l}-1.345 \\
(-8.62)\end{array}$ & $\begin{array}{l}-1.354 \\
(-9.07)\end{array}$ & $\begin{array}{l}-1.348 \\
(-8.86)\end{array}$ \\
\hline$I C C A$ & $\begin{array}{c}0.650 \\
(3.34)\end{array}$ & $\begin{array}{r}0.811 \\
(4.28)\end{array}$ & $\begin{array}{c}0.798 \\
(4.16)\end{array}$ & $\begin{array}{c}0.562 \\
(3.21)\end{array}$ & $\begin{array}{c}0.678 \\
(3.91)\end{array}$ & $\begin{array}{r}0.671 \\
(3.80)\end{array}$ \\
\hline$I V A$ & $\begin{array}{r}0.765 \\
(12.54)\end{array}$ & $\begin{array}{r}0.804 \\
(13.36)\end{array}$ & $\begin{array}{r}0.799 \\
(13.05)\end{array}$ & $\begin{array}{r}0.758 \\
(13.21)\end{array}$ & $\begin{array}{r}0.793 \\
(13.87)\end{array}$ & $\begin{array}{r}0.790 \\
(13.60)\end{array}$ \\
\hline$D / A$ & $\begin{array}{c}7.848 \\
(2.70)\end{array}$ & $\cdots$ & $\begin{array}{r}1.949 \\
(0.51)\end{array}$ & $\begin{array}{l}6.605 \\
(2.57)\end{array}$ & $\cdots$ & $\begin{array}{r}0.888 \\
(0.24)\end{array}$ \\
\hline $\boldsymbol{T}$ & ... & $\begin{array}{l}0.015 \\
(3.76)\end{array}$ & $\begin{array}{r}0.013 \\
(2.31)\end{array}$ & $\cdots$ & $\begin{array}{l}0.012 \\
(3.46)\end{array}$ & $\begin{array}{r}0.011 \\
(2.17)\end{array}$ \\
\hline \multicolumn{7}{|l|}{ Regression statistic } \\
\hline $\begin{array}{l}\vec{R}^{2} \\
\text { Standard error }\end{array}$ & 0.98 & 0.98 & 0.98 & & 0.98 & 0.98 \\
\hline $\begin{array}{l}\text { Standard error } \\
\text { Durbin-Watson }\end{array}$ & $\begin{array}{l}0.16 \\
1.71\end{array}$ & $\begin{array}{l}0.16 \\
1.87\end{array}$ & $\begin{array}{l}0.16 \\
1.85\end{array}$ & $\begin{array}{l}0.15 \\
1.73\end{array}$ & $\begin{array}{l}0.15 \\
1.88\end{array}$ & $\begin{array}{l}0.15 \\
1.87\end{array}$ \\
\hline$\rho$ & 0.86 & 0.85 & 0.85 & 0.84 & 0.84 & 0.84 \\
\hline$R_{u}^{2} \circ$ & 0.88 & 0.86 & 0.86 & 0.88 & 0.87 & 0.87 \\
\hline Standard error & 0.42 & 0.45 & 0.45 & 0.41 & 0.43 & 0.44 \\
\hline Durbin-Watson & 0.16 & 0.14 & 0.14 & 0.15 & 0.14 & 0.14 \\
\hline
\end{tabular}

Sources: The numerator of $A T R$ is from U.S. Bureau of Economic Analysis, National Income and Product Accounts of the United States, 1929-74: Statistical Tables (GPO, 1977), table 1.15, and Survey of Current Business, various issues, while the denominator is "other assets" from table 1 above, column $2 ; D U$ is available from the U.S. Bureau of Labor Statistics; $T R$ was derived by the author and is available from him in a longer version of this appendix; remaining variables are from sources listed in table 2 or 3 above. All variables are defined in the text of the appendix. TR, ICCA, and IVA are divided by "other assets." and expressed in percentage terms. $C U$ is entered minus its mean value of 0.833 .

$A T R$ for 1953:4 was raised from 3.30 to 3.90 percent to adjust for post-Korean conversion costs and the anomalous anticipation of expenses encouraged by the expiration of the excess-profits tax at the end of that quarter. For a justification, see Survey of Current Business, vol. 34 (May 1954), p. 6. After the adjustment, the prediction error for that quarter is still almost twice the standard error of estimate. The regression coefficients and significance levels obtained with this adjustment turned out to be very close to those obtained for the subsample starting in 1954:1.

a. The dependent variable is expressed as a percent of "other assets." The method of estimation is ordinary least squares with a correction for first-order autocorrelation using the Cochrane-Orcutt technique throughout. The numbers in parentheses are $t$ statistics.

b. For a description of the lag structure, see the appendix text.

c. As explained in the text, $R_{u}^{2}$ is not fitted but calculated as $1-\left[(N-1) /(N-K)\left(\Sigma u^{2} / \Sigma y^{2}\right)\right] . N-K$ indicates the number of degrees of freedom from $N$ observations, $y$ is the dependent variable (in mean deviants), and $u$ is the difference between $y$ and the value of $y$ predicted with the set of coefficients found in the regression af ter setting $\rho$ equal to zero in solving for the predicted value of $y$. 
nificance while $D / A$ does not. There is some evidence, therefore, that the underlying after-tax rate of return has risen over time. This finding is not entirely unexpected since the effective tax rate has declined. If the coefficient on $T$ is to be believed, the cumulative rise in $A T R$ amounts to at least 1 percentage point from 1952:1 to 1976:4, or to almost 20 percent of the annualized mean of 5.27 over this period. This finding holds, of course, only ceteris paribus in a world in which inflation at least has been decidedly impar. If $I V A$ is eliminated from the regressions containing $T$ in table A-1, the coefficient on $T$ is always completely insignificant.

Overall, the fit of the equations is very close, particularly in view of the fact that $A T R$ varied over a wide range, from 2.75 percent to 7.93 percent of net capital. The "forecasting" ability of the coefficients other than $\rho$ found in the AOLS regressions is also good since $\bar{R}_{u}^{2}$ is still over 85 percent when the contribution of the first-order Markov process to reducing the unexplained sum of squares is denied. For these reasons it may be interesting to interpret the remaining regression coefficients, on $C U$ and $D U$, for which a priori expectations extend only to sign. Increasing unemployment by 1 percentage point reduces $A T R$ in that quarter by about 0.2 , or by around 4 percent of its mean of 5.3. Lowering $C U$ by 0.025 , or by 3 percent of its original mean of 0.833 , on the other hand, reduces $A T R$ by 0.3 , and the effect persists. This result clearly shows that capacity utilization must be regarded as a strong candidate for inclusion in the equations for capital-goods orders and investment. The same holds for most of the explicit tax-change variables in $T R$ and the implicit tax variables $I C C A, I V A$, and $D / A$, though $D / A$ was found to interact strongly with the time trend. Furthermore, like temporary tax changes, the inventory valuation adjustment may reflect mainly transitory forces. It would have to affect the profitability not only of past but also of future investments if it is to be as important a determinant of the rate of capital-goods orders as it appears to be of the actual after-tax rate of return. The same comment would apply to cyclical indicators, such as capacity utilization, if businessmen still had faith that swings in business conditions follow the laws of the pendulum, for in that case present conditions would be a poor predictor of future business conditions. ${ }^{64}$

64. A longer version of this appendix and the paper by Green and Watson cited in note 34 , which was originally prepared for this study, are available from the author. 


\section{Comments and Discussion}

Michael C. Lovell: If proof were needed that James Tobin's $q$ has come of age, it is offered by the 1977 Economic Report of the President, which presents in table 1 the ratio of the market value of corporate assets to their replacement cost. George von Furstenberg has done us a great service by providing a sterling account of what factors determine $q$ and how $q$ in turn influences investment behavior.

Von Furstenberg's quarterly $q$ series, spanning 1952 through 1976, is provocative from three perspectives. First, a self-appointed shadow open market committee that defined policy as "stabilizing" when $q$ is higher at the trough than at the preceding peak of the business cycle would obtain a rather mixed story. His series suggests that, by this definition, policy was stabilizing in 1954 and 1961 but destabilizing in 1958, 1970, and 1975. (However, my own view is that one should not grade either monetary or fiscal policy in terms of $q$ or any other single index. Stabilization strategies should be evaluated by comparing alternative simulation paths generated with an appropriately specified econometric model.)

Second, a future economic historian interested in appraising the contributions of the 1964 tax cut will find the analysis confounded by the record $q$ attained in 1965. Was the historic high the result of the tax cut or was it the consequence of monetary policy?

Third, current and recent levels of $q$ are exceedingly low, and indicate that policy in 1975 was at its tightest since the Korean War. The 1977 Economic Report concludes that the phenomenally low $q$ should be combated with a cut in the corporate profits tax and the restoration of confi- 
dence. But Tobin and Brainard have argued that "tight anti-inflationary monetary policies were undoubtedly responsible." 1

If $q$ is indeed the fulcrum by which monetary and fiscal policy exert leverage on the economy, it is important to find out what determines it. Von Furstenberg's regression results indicate that changes in depreciation allowances and temporary changes in tax rates do not influence $q$ appreciably. However, a permanent change in the corporate tax rate has a statistically significant effect. A 10 percent cut in the corporate profits tax would increase $q$ by about 4 percent during the first quarter it was in effect. This supports the policy recommendation presented in the 1977 Economic Report. In perspective, however, that is not a tremendous bang for the buck, and the case for changes in the permanent rate is strongest as a means of combating secular stagnation rather than economic fluctuations.

I am concerned with two problems with these regressions. First, monetary variables are not included. I do not believe that monetary and fiscal variables are uncorrelated, and I suspect that the coefficients on the fiscal variables are exaggerated as a result of this omission; that is, the role of fiscal policy is overstated. Second, if it is true that inflationary factors influence $q$, as the analysis assumes, it may also be true that $q$ influences inflation via its effects on investment and aggregate activity; single-equation regressions cannot untangle all of these interactions. Thus, the regressions in table 3 suggest that one might predict $q$ fairly closely from the contemporary movements of the variables included in the regressions, but they do not answer many of the interesting structural questions.

As I understand it, $q$ is supposed to have its primary impact on aggregate demand through its effects on investment spending. I am struck by the similarities between $q$ theory and the neoclassical approach of Dale Jorgenson, Robert Hall, and others. In particular, they share the following characteristics: (1) Both theories try to summarize the firm's target in terms of a single variable, $q$ for Tobin and the ratio of current output to user cost in the neoclassical model. Can it be all that simple? (2) Neither approach works out the dynamics of the adjustment process

1. James Tobin and William C. Brainard, "Asset Markets and the Cost of Capital," in Bela Balassa and Richard Nelson, eds., Economic Progress, Private Values, and Public Policy, Essays in Honor of William Fellner (Amsterdam: North-Holland, 1977), p. 262. 
within the context of a carefully articulated optimization framework that would specifically incorporate the process of expectation formation and adjustment costs. In this respect, both theories are dominated by a number of contributions that have derived the optimal time path of adjustment simultaneously with the determination of the properties of the ultimate long-run equilibrium. ${ }^{2}$

If you think that Jorgenson and his coworkers have succeeded in measuring user cost with high precision; if you buy the convenience of the Cobb-Douglas production function; and if you are not worried about reliance solely on the current level to the exclusion of the anticipated time profile of sales in defining the equilibrium stock-then you may not need to pray hard for the success of $q$. My own suspicion is that the $q$ approach may be particularly fruitful for cross-sectional work because it does not rely on the assumption that the firm's sales are exogenous. For aggregate time series, much may depend on the relative seriousness of measurement errors in trying to determine $q$ on the one hand and user cost on the other. While $q$ does have in its favor the use of market estimates of the long-run prospects of the firm rather than reliance on the ratio of current sales to user cost, there is the difficulty of distinguishing marginal from average $q$; the replacement cost of net fixed assets seems a particularly difficult thing to measure.

My own view is that the empirical results in this paper, while fascinating, are not as negative for $q$ theory as the author implies. Capacity utilization also appears important, but it stars in the orders equations more than in the investment equations; and it may work there because the fixed coefficients of the Almon lag are inadequate to capture the stretchout that occurs when the machinery industry is operating all out. The replication of Popkin's results suggests that something more is needed. I regard the regressions that include both $q$ and capacity utilization as the most informative in tables 4 and 5; note that $q$ always has a significant coefficient even when it is placed in tandem with the lag and accelerator effect of capacity utilization and a host of other variables. The regressions

2. Charles C. Holt and others, Planning Production, Inventories, and Work Force (Prentice-Hall, 1960); Robert Eisner and Robert H. Strotz, "Determinants of Business Investment," in Daniel B. Suits and others, Impacts of Monetary Policy, a series of research studies prepared for the Commission on Money and Credit (PrenticeHall, 1963), pp. 59-233; Robert E. Lucas, Jr., "Optimal Investment Policy and the Flexible Accelerator," International Economic Review, vol. 8 (February 1967), pp. 78-85. 
with adjusted $q$ make $q$ look somewhat less important, but these regressions use the residuals obtained from an auxiliary regression of $q$ on all the other explanatory variables except $G E / G P E$ in table 4; this procedure doesn't change the standard error of $q$ very much, but it does reduce its regression coefficient and hence its level of significance. But these adjusted $q$ regressions give $q$ last pickings beyond what all the other variables can do, and I discount them. (We could tilt the story the other way by replacing capacity utilization with the residuals obtained when it is regressed on $q$ and other variables as well; this would make $C U$ look less important and puff $q$. The procedure is also suspect if the first regression of table 3 does not adequately explain the generation of $q$.)

Von Furstenberg warns us that the autorogressive transformation regressions may not be adequate. It should be noted that even if the disturbances are not distributed independently of each other, the leastsquares approach does not lead to inconsistent estimates of the parameters of the regression model; however, the least-squares estimates of the parameters will be inefficient and the customary $t$ coefficients will be distorted. The autoregressive transformation corrects for this if the error term is generated by a first-order autoregressive process. The author applies a test, indicating that the stochastic disturbance is not first-order autoregressive; however, significance levels of his test statistic are not available. I am not persuaded that any evidence of "inconsistent estimation" has been uncovered. I think that AOLS should have been abandoned sooner with a less determined rescue operation of adding variables. The use of other diagnostic procedures and further investigation may reveal that the stochastic process generating the error terms is more complicated, possibly moving average, and I think this should be checked out. It is also possible that the problem arises from misspecification-perhaps the Almon lag structure is too restrictive a way of modeling the lag structure; $q$ deserves to be coupled with rational distributed lags in explaining investment. Pending further evidence on these alternatives I think we must suspend judgment on the merits of $q$.

James Tobin: I'm not sure that Lovell is quite correct to speak of the coming of age of an idea that goes back at least as far as Wicksell, not to mention Keynes. But it seems that $q$ has come of age-every recent session of this panel seems to have had a paper relating to it.

Last time, Robert Hall attempted to show that it was really a neo- 
classical theory, à la Jorgenson. His point seemed to be that only incomplete information and delivery lags accounted for apparent disequilibrium values of $q$ and for their relation to investment in regressions. Otherwise, investment would keep $q$ at one. Now $q$ is being hit from the opposite side: von Furstenberg is saying that, in the aggregate, $q$ has very little to do with investment. The forces that keep $q$ at par are very weak; to paraphrase his argument, securities-market valuation is a side show.

Von Furstenberg has performed extremely useful empirical calculations. He deserves our thanks for his improvements on our previous estimates and, in particular, for the care with which he handled the valuation of bonds.

The paper seems to have two principal messages: One is that only relative $q$ matters; relative $q$ s determine the allocation of investment among sectors, industries, and firms, but overall $q$ has little or no effect on overall investment. The other message is that, of the factors that influence $q$, those related to current and prospective earnings-to the marginal efficiency of capital - do affect investment, whereas the rate at which earnings are discounted - the cost of capital—does not. Taken together, these propositions imply that monetary policy and financial variables are irrelevant to aggregate investment, except insofar as they may influence profits and profitability by affecting economic activity through some different channel-for example, housing. Von Furstenberg's explanation of nonresidential investment seems, in effect, to revert to the cash-flow and liquidity theories of Meyer and Kuh. While I believe that liquidity is important in the investment story, I do not find the pure cash-flow model theoretically appealing or empirically convincing. Von Furstenberg has added no new evidence in its favor.

The notion that $q$ does not matter in the aggregate has some credibility because the downward trend in $q$ since the mid-1960s has not been accompanied by a comparable downward trend in capital investment. I too find this a puzzle. It is true that regressions such as Ciccolo's, successful as they have been in forecasts, are virtually first-difference equations; the rho coefficient is almost equal to one. It is also true that without correction for serial correlation of residuals, those regressions seriously underpredict investment in the 1950s. I agree that improvements in specifications are required. To that end Ciccolo, some of my colleagues at Yale, and I have been trying to incorporate tax credits and other tax changes into the relationship of investment to $q$. We are also trying to 
model in an appropriate nonlinear way our hypothesis that the relationship reflects, at least in part, the way in which adjustment costs vary with the speed of capital formation.

Like Lovell, I do not understand the logic of using "adjusted $q$ "variation of $q$ that cannot be explained by other variables-to explain investment. To the extent that those other variables are the same ones used in the investment equation, the procedure is innocuous but redundant. However, they are not quite the same. So why is this particular variable only the residual claimant? Nor do I follow the argument that, since other variables explain 85 percent of the variance of $q$, nothing is left for financial variables to explain. It may very well be that a group of financial variables, or any set of variables taken at random out of a data bank, could also account for 85 percent of the variance.

In the article Lovell mentioned, Brainard and I used cross-sections of firms year by year and tried to control profits and expected profits to see how the market would value a firm of constant and representative earnings and other characteristics. We found that a lot of year-to-year variation remained in $q$, evidently due to monetary or financial factors, or, to be more cautious, to factors that were not among our measures of the fundamental firm characteristics used in the valuation regressions. In 1974 , for example, the $q$ of our hypothetical representative firm, one with the same profits and profit prospects as in previous years, declined sharply. Surely this decline was heavily influenced by monetary policies and events during that year.

One explanation of the weakness of investment in 1974 and since is the collapse of $q$, a collapse partly attributable to monetary and financial factors. Von Furstenberg's alternative is that investment has been deterred by the increased bite of corporate taxation incident to inflation. Most of the statistical action of the variables he uses to measure this effect occurred during the last two years of his sample. During this period, $q$ was also low, and a number of other well-known extraordinary events occurred as well. Consequently, we are confronted with an acute ambiguity of identification.

Several of von Furstenberg's independent variables, notably the capital consumption adjustment (CCA) and IVA, are meant to capture the negative effects of inflation on investment. I am not sure of the logic of his specification. The losses due to CCA have already taken place. Only if it were anticipated that similar disappointing surprises would recur 
would historical values of CCA be appropriate in an investment equation. Likewise, the damage to profits from inflation attributable to IVA occurs only when firms stubbornly stick to FIFO and hence incur higher taxes.

There is a similar weakness in von Furstenberg's use of the debt-asset ratio. This is included in the regressions along with the tax variables only because it might be a source of countervailing gains from inflation. But these too are bygones unless comparable inflation-induced increases of nominal interest rates are expected in future. Incidentally, it seems strange that von Furstenberg is so concerned about the value of the tax deduction for interest when he does not use interest rates or related variables as an explanatory variable for investment.

Von Furstenberg's investment regressions do not substantiate his claim that the other variables render $q$ redundant. Even in the adjusted versions of the equations, $q$ maintains its value and significance. The coefficients obtained by von Furstenberg on $q$ are quite robust and are generally in the range of estimates by others, such as Ciccolo-implying an elasticity of investment with respect to $q$ of around 0.7.

I am not surprised by von Furstenberg's observation that $q$ itself is not easily predictable. Keynes rightly emphasized that long-range profit expectations contain, for all practical purposes, a high degree of autonomy or exogeneity. They cannot simply be forecast on the basis of past events. Von Furstenberg himself stresses the importance of contemporary capacity utilization, but admits he is puzzled as to why it should be important for long-lived investments. After all, the effect of a year or two of temporary excess capacity on the marginal efficiency of capital should not be large. The importance of the variable must derive from expectations. But expectations are likely to be related differently to utilization in 1977 than they were in 1937, 1957, or 1967. The current business cycle is unlike any other in the postwar years. It seems to have destroyed business confidence that recessions and slumps are temporary aberrations. An advantage of $q$ is that it registers those expectations and balances them against capital costs.

I doubt that, in the final analysis, the answer lies in a single letter of the alphabet, be it $q$ or $M$ or any other. We do not observe marginal $q$, and many things change the relationship between marginal $q$ and average $q$. In addition, the relation of $q$ to investment depends on adjustment costs and these may change over time.

On a technical matter, I think that von Furstenberg gives too much 
emphasis to his $R_{u}^{2}$ calculation. He is comparing the variation of the dependent variable from its mean with the variance of residuals from the AOLS regression computed on the assumption that the previous year's residual is zero. But the latter residuals need not sum to zero in any particular sample. If there is a large residual in the period immediately preceding the sample period (as there was in Ciccolo's investment- $q$ regressions), the sample residuals may have a nonzero mean and a larger variance around zero than the deviations of the dependent variable from its mean. It seems to me more appropriate to subtract the mean residual from each of the residuals in carrying out this computation.

I would also like to note that measurement problems-in particular, those associated with the real capital stock-make it impossible to be sure that the natural or normal value of a statistical $q$ is any particular number-one, less than one, or more than one. Von Furstenberg points out that in a model with vintage capital, only the newest capital would be expected to have $q$ s greater than or equal to one, so that the average $q$ would be below one. But there are also opposing factors, such as the market capitalization of nontangible assets, goodwill, and monopoly rights, that would push the measured value of $q$ above one. Fortunately, what matters for empirical work is the movement of $q$, not its average level.

In conclusion, on von Furstenberg's view, with inflation tapering off and capacity utilization improving in the current recovery, investment should do well. On the other hand, for confidence, monetary, or other reasons, $q$ is still low, and so I expect a weak investment performance. Perhaps we should make a bet. For the good of the economy, though, I hope I turn out to be wrong.

George M. von Furstenberg: Lovell and Tobin have both criticized my use of adjusted $q$ as a variable in investment equations. They are not alone; I have heard even stronger criticisms from other participants. That is clearly the most controversial piece of methodology in my paper, and hence I would like to explain my reasoning on it.

There are conceivably factors that influence investment rates without affecting $q$, other factors that influence $q$ without affecting investment, and still others that simultaneously or sequentially influence investment rates and $q$. If it were known that the last factors affect investment only conditionally, or to the extent that they first affect $q$, a hierarchical structure of 
causation would be implied that would have investment rates linked properly to $q$ and not to these other variables, whose influence on $q$ may be changing. The existence of such an exclusive hierarchical relationship cannot be disproved by estimating the effects of the correlates of $q$ on investment by running them jointly with the adjusted $q$ and finding their coefficients to be significant. Rather, it is disproved by finding that including these other variables raises the explanatory power of the estimating equation and reduces the degree of autocorrelation of the error terms.

Assume, however, that the opposite is known and that $q$ is guaranteed to have no effect on investment though it is (imperfectly) correlated with several or all of the factors influencing investment. Then running unadjusted $q$ together with these other variables would distort their coefficients to the extent that coefficient splitting caused the coefficient estimated on $q$ to be nonzero. In that case, runs with the adjusted $q$ would yield the correct coefficients on these other variables. Of course, one would do even better by simply dropping $q$ altogether. However, suppose that there are some factors not identified in the regression that influence $q$ and thereby investment rates; then even though changes in $q$ have no causal effect on investment rates, runs with adjusted $q$ would continue to be justified to the extent that such changes arise from any other factor included in the regression. Whether one would like to look at the coefficient set estimated with the adjusted or the unadjusted $q$ thus depends on one's priors, and I felt the reader should be given a choice. Thanks to the discussants, I now recognize, however, that I may have prejudiced this choice by emphasizing the results obtained with the adjusted $q$ in multiple regressions.

\section{General Discussion}

John Shoven raised the problem of accurately measuring the marginal $q$ that is relevant to investment decisions. He suggested that, in the face of a significant technological innovation or some other structural shift in the economy, such as the rise in oil prices, existing capital might fall in value, average $q$ would drop, but marginal $q$ might rise reflecting an increase in the attractiveness of new investment.

Robert Hall felt that the persistence of $q$ at disequilibrium levels for long periods of time was a puzzle as perplexing as the persistence of disequilibrium unemployment rates. He reiterated his conviction that al- 
legedly long adjustment lags in the investment process did not provide a convincing explanation. Alan Greenspan did not regard such persistence as a vexing problem: the market might well harbor optimistic or pessimistic notions that took time to dissipate. He cited the long-sustained postwar concern about stagnation- - "the Montgomery Ward syndrome." Robert J. Gordon agreed, noting that underestimates persisted in postwar inflationary expectations since people kept anticipating recessions and price declines.

Greenspan also reported that he had found it useful to use average stock prices divided by the cost of new plant and equipment as an investment indicator. Obviously, the level of that ratio had no meaningful interpretation (unlike the level of $q$ ), but its movements over time resembled those of $q$. He believed that this simpler measure might actually be preferable, since he was skeptical of the equal weighting by $q$ of the valuation of debt and equity securities.

Various participants explored the meaning of corporate managers' bucking the tides of the capital market with their investment decisions. Von Furstenberg elaborated his view that they might well disagree with the verdict about the economy that the market was conveying. They might believe that it was displaying an overly sensitive reaction to short-run cyclical conditions, and they might expect a good profit from investing that would convince the market in the future, in spite of the low current level of $q$. Hall expressed his dissatisfaction with the implication that managers are willing to invest when $q$ is 0.7 , thereby instantly losing 30 percent of their stockholders' money. But von Furstenberg stressed the obvious fact that they did not simply pay out all their cash in dividends when $q$ was low and did not even increase the payout ratio measured after adding gains from the reduction in real indebtedness to the profits of nonfinancial corporations. William Fellner distinguished between the decision to invest and the method of financing investment. He found it plausible that, if firms were relatively bullish about their own stocks in a depressed market, they would wait before selling equity but might invest and finance that investment by other means in the interim. Arthur Okun pointed out that firms always have the alternative of buying back their own equity or of making acquisition offers to other firms when they are more optimistic than the market. It was puzzling to him that firms do not buy some of their own equity more often. Hall suggested that another aspect of today's marketplace might buoy investment in the face of a low $q$. It might well 
be rational for firms to invest in physical assets even at low returns when the alternative was holding a financial asset with a negative or zero real after-tax rate of return.

Martin Feldstein differed with von Furstenberg's characterization of his results as having cast doubt upon the explanatory power of $q$. Pointing to the size and significance of the coefficients, Feldstein believed that the paper had shown that $q$ was indeed important. To be sure, it was difficult to predict $q$ or to link its movements clearly to monetary and fiscal policy variables. Feldstein expressed some reservations about the statistical estimates. Although von Furstenberg had been meticulous in his treatment of the autocorrelation problem, in Feldstein's view he had not taken seriously enough the problems raised by the endogenous nature of some of the variables; those called for methods other than ordinary least squares.

Von Furstenberg stressed that the explanatory power of the investment equation that used $q$ derived from its correcting highly serially correlated errors. The equation contained an initially huge and systematic underprediction for the period 1952-64, whose extent could be gauged by noting that the equation predicted a level of investment less than half of the actual value in the first period. But the very high value of $\rho$ introduces a statistical self-correction process, and the equation gets credit for this as part of its explained variation. Agreeing with the author on the seriousness of this defect, Frederic Mishkin noted that major errors might occur when an equation with this property was used for longer-term forecasts where less use could be made of error terms. William Brainard agreed that the pattern of errors suggests a specification error, but noted that when the $q$ equation was used to forecast out of sample up to eight quarters ahead it had performed quite well, even without the use of the "unavoidable" out-of-sample forecast errors. Nevertheless, it is apparent that if the equation is to be used for such purposes, more attention should be paid to finding a structural specification that does not depend so heavily on the first-order autoregressive correction, and that would presumably do better in minimizing the longer-term forecast errors. 